\title{
Review
}

\section{Advances in Purpurin 18 Research: On Cancer Therapy}

\author{
Vladimíra Pavlíčková ${ }^{1}\left[\right.$, Jan Škubník ${ }^{1}$, Michal Jurášek ${ }^{2}$ (1) and Silvie Rimpelová ${ }^{1, *(1)}$ \\ 1 Department of Biochemistry and Microbiology, University of Chemistry and Technology Prague, Technická 5, \\ 16628 Prague 6, Czech Republic; vladimira.pavlickova@vscht.cz (V.P.); jan.skubnik@vscht.cz (J.Š.) \\ 2 Department of Chemistry of Natural Compounds, University of Chemistry and Technology Prague, \\ Technická 5, 16628 Prague 6, Czech Republic; michal.jurasek@vscht.cz \\ * Correspondence: silvie.rimpelova@vscht.cz
}

\section{check for}

updates

Citation: Pavlíčková, V.; Škubník, J.; Jurášek, M.; Rimpelová, S. Advances in Purpurin 18 Research: On Cancer Therapy. Appl. Sci. 2021, 11, 2254. https://doi.org/10.3390/app11052254

Academic Editor: Genoveffa Nuzzo

Received: 16 February 2021

Accepted: 28 February 2021

Published: 4 March 2021

Publisher's Note: MDPI stays neutral with regard to jurisdictional claims in published maps and institutional affiliations.

Copyright: (c) 2021 by the authors. Licensee MDPI, Basel, Switzerland. This article is an open access article distributed under the terms and conditions of the Creative Commons Attribution (CC BY) license (https:// creativecommons.org/licenses/by/ $4.0 /)$.

\begin{abstract}
How to make cancer treatment more efficient and enhance the patient's outcome? By multimodal therapy, theranostics, or personalized medicine? These are questions asked by scientists and doctors worldwide. However, finding new unique approaches and options for cancer treatment as well as new selective therapeutics is very challenging. More frequently, researchers "go back in time" and use already known and well-described compounds/drugs, the structure of which further derivatize to "improve" their properties, extend the use of existing drugs to new indications, or even to obtain a completely novel drug. Natural substances, especially marine products, are a great inspiration in the discovery and development of novel anticancer drugs. These can be used in many modern approaches, either as photo- and sonosensitizers in photodynamic and sonodynamic cancer therapy, respectively, or in tumor imaging and diagnosis. This review is focused on a very potent natural product, the chlorophyll metabolite purpurin 18, and its derivatives, which is well suitable for all the mentioned applications. Purpurin 18 can be easily isolated from green plants of all kinds ranging from seaweed to spinach leaves and, thus, it presents an economically feasible source for a very promising anticancer drug.
\end{abstract}

Keywords: cancer therapy; gold nanoparticles; marine products; natural products; photosensitizer; purpurin 18; reactive oxygen species; seaweed

\section{Introduction}

Cancer and the lack of an effective treatment have been global problems for many years. Current treatment approaches are based on decades-old methods such as tumor resection, radiotherapy, and classic chemotherapy, which are not always effective and, thus, cancer remains to be the leading cause of death worldwide [1]. Significant problems of current anticancer therapy are especially the low selectivity of anticancer drugs and their high systemic toxicity, which leads to damage of healthy cells. A severe obstacle in cancer treatment is also the frequent emergence of resistance to individual chemotherapeutics, whether it is a natural resistance or acquired, for example, due to insufficient drug concentration at the tumor site. Modern strategies for cancer treatment include early diagnosis of the disease as well as effective targeted treatment with minimal side effects. To the long-known methods with such benefits belongs photodynamic therapy (PDT), which is based on the application of a photosensitive substance (PS), which after excitation by light and reaction with cellular oxygen generates cytotoxic reactive oxygen species (ROS) [2]. Very similar methods closely related to PDT are photothermal therapy (PTT) and sonodynamic therapy (SDT). In PTT, the light energy absorbed by a PS is converted into thermal energy. The generated heat then warms the target tumor cells, which leads to their damage and death. In the case of SDT, instead of light, ultrasound waves are applied to activate the drug used, a so-called sonosensitizer (ST). Then, the activated ST eliminates the target cells by a similar mechanism to that of a PS. In addition to SDT, another method utilizes acoustic ultrasonic waves-photoacoustic imaging (PAI). However, as for PAI, the ultrasound 
waves do not serve as drug activators but as a measurement output. In the case of PAI, the drug is activated by a pulsed laser, and based on the energy conversion, ultrasonic waves are subsequently generated, which are monitored to form an image. Owing to the high resolution of PAI and the possibility of deep penetration into the tissues, this method is a promising technique, especially in terms of tumor diagnosis. However, for all these methods, very specific compounds, e.g., of natural origin, must be sought.

Natural compounds for cancer therapies have often a plant origin, but many of them come also from marine organisms and seaweed [3]. Many substances isolated from seaweed have been shown to have significant health benefits and are thus often used in the cosmetics or food and pharmaceutical industries. Seaweed can be classified as an important source of polyunsaturated fatty acids, vitamins, enzymes but also natural pigments such as chlorophylls, carotenoids, and quinones [4-8]. Evidence suggests that the most important are green pigments-chlorophylls. These occur in brown, red, and green seaweed (Phaeophyceae, Rhodophyceae, and Chlorophyceae) [9]. Due to the high content of chlorophyll (Chl; 565 to $2000 \mathrm{mg} \cdot \mathrm{kg}^{-1}$ of dried biomass) in seaweed [8] and undemanding cultivation methods on a large scale, seaweed is a favorable source for $\mathrm{Chl}$ production. Dried seaweed biomass can be used to extract Chl utilizing organic solvents or supercritical extraction [10]. The Chl thus obtained can then be chemically modified to give its derivatives and metabolites, one of which is purpurin 18 (pu18), which is well known for its unique properties and great potential in anticancer therapy.

This review aims to detail the most recent advances in pu18 anticancer research, with emphasis especially on PDT, PTT, and PAI. Moreover, biosynthesis of pu18 and novel anticancer derivatives of pu18 are also discussed.

\section{From Plant Dyes to Medicines}

$\mathrm{Chl}$ is perhaps the most famous green pigment that each of us comes across daily. The most common and most important in terms of photosynthesis is blue-green chlorophyll $a$ $(\mathrm{Chl} a)$, which absorbs light energy at wavelengths with a maximum of 660-665 nm [10,11]. Other types are yellow-green chlorophyll $b$ (Chlb, maximum absorbance at 642-652 nm), which occurs in green seaweed, and chlorophyll $c$ with a maximum absorbance of 447-452 nm. The fourth type, chlorophyll $d$ absorbs at far-red wavelengths around $710 \mathrm{~nm}$ and occurs in cyanobacteria and red seaweed [12]. Chl plays a key role in plant photosynthesis and its decay is an important catabolic process of leaf aging and fruit ripening. However, the biochemical processes by which $\mathrm{Chl}$ is degraded have been unknown for many years, and it was not until the identification of the major metabolites that the whole process was elucidated. It is now known that in the first phase, enzymatic reactions of color pigments take place. The pigments serve as substrates for the formation of a colorless, blue fluorescent decomposition product, called primary fluorescent $\mathrm{Chl}$ catabolite. One of the key steps in this metabolic pathway is the enzymatic conversion of Chlb to Chla, also known as the $\mathrm{Chl}$ cycle $[13,14]$. The central magnesium atom is further removed from the Chla molecule by magnesium dechelatase [EC 4.99.1.10] to form pheophytin $a$, which passes into another colored product pheophorbide $a(\mathrm{~Pb} a)$. Through other enzyme-catalyzed reactions, $\mathrm{Pb} a$ is converted to red Chl catabolite and further to primary fluorescent $\mathrm{Chl}$ catabolite. $\mathrm{Chl}$ degradation usually results in non-enzymatic isomerization of modified fluorescent $\mathrm{Chl}$ catabolites to their respective nonfluorescent $\mathrm{Chl}$ catabolite, which is transported into plant cell vacuoles for further processing (Figure 1) [15].

As the structural formulas are shown in Figure 1, it is apparent that $\mathrm{Chl}$ is a porphyrin with a cyclic tetrapyrrole nucleus. Its metabolites are characterized by $18 \pi$ electrons in the aromatic ring with a conjugated double bond system. This structural arrangement predetermines Chl metabolites to be PSs with the possibility of use for example in cancer therapy. Chla itself is characterized by a high extinction coefficient at $661 \mathrm{~nm}$ [16] and good singlet oxygen production. However, what limits its further use is its low thermal stability, proneness to degradation due to light irradiation, and also low stability at acidic $\mathrm{pH}$. At the same time, it was found that Chla exhibits lower thermal and $\mathrm{pH}$ stability than 
Chl $b$ [17]. Therefore, from the point of view of a PS, its natural degradation products and their semi-synthetic derivatives are more interesting for potential medicinal application.

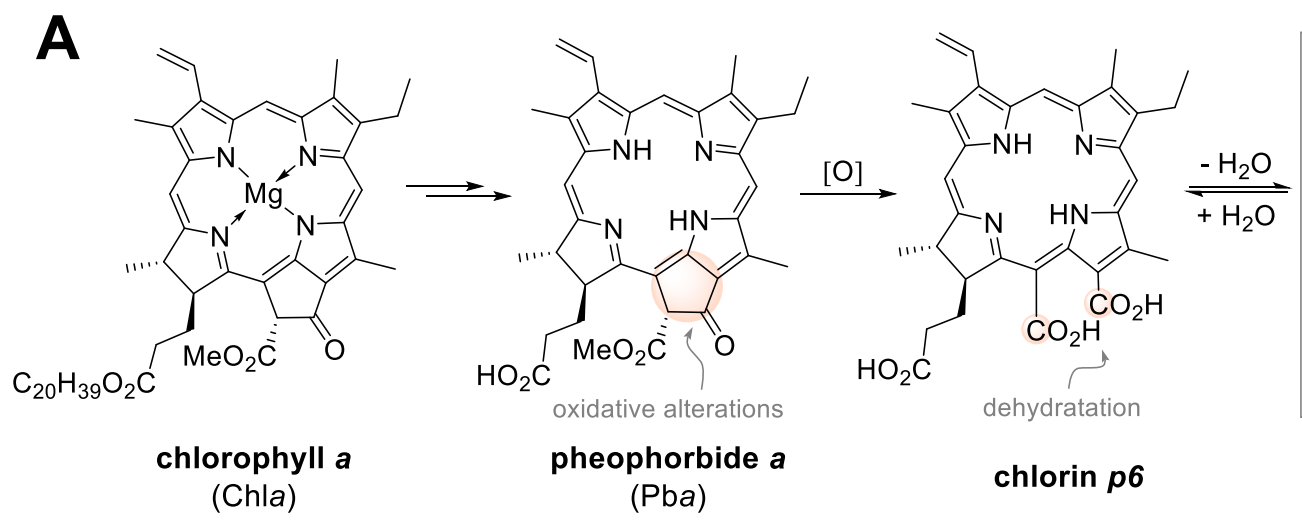

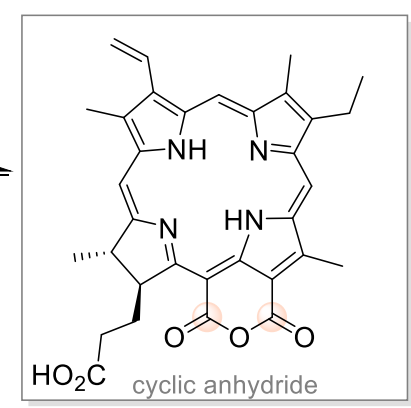

purpurin 18 (Pu18)

\section{B}

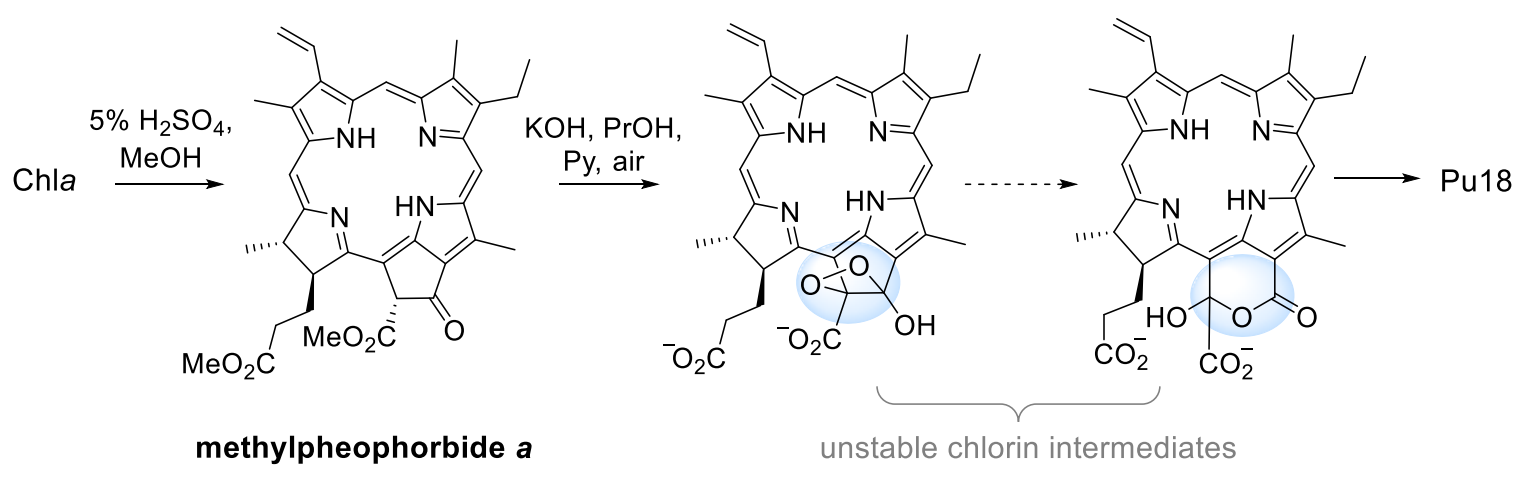

Figure 1. The biological degradation process of chlorophyll $a$ leads to purpurin 18 (pu18, panel A) and chemical transformation of chlorophyll $a$ to pu18 (panel B).

\section{Purpurin 18 and Cancer Treatment}

One of such degradation products of $\mathrm{Chl}$ is the already aforementioned pu18, a photosensitive chlorin substance naturally occurring in, for example, spinach leaves [18], cyanobacterium Spirulina maxima [19], Japanese carpet shells Ruditapes phlippinarum [20], brown mussel Perna perna [21], or in a whole series of edible seaweed [22]. It has been confirmed that pu18 can be even observed from geological samples of sediments [23]. Considering mainly its photochemical properties, pu18 represents a potentially useful substance for cancer phototherapy. What is mainly advantageous is its maximum absorption at $700 \mathrm{~nm}$, as the light of such wavelength penetrates deep into the tumor tissue [24]. Unfortunately, even despite this benefit, pu18 has not been applied in clinical practice, yet, since it exhibits high hydrophobicity. Therefore, tremendous effort has been made to derivatize pu18 structure to overcome this solubility limitation. The chemical structure of pu18 offers great options for structural modifications (Figure 2). One example among many is linking pu18 with a peptide by a reaction of the carboxyl group of propionic acid of pu18 and amidogen radical of the peptide. For example, by linking pu18 with arginine-rich peptides, conjugates with higher hydrophilicity can be prepared, which, besides, exert modified aggregation properties (increased with a higher number of arginine units) and well-ordered assembly [25]. That is, indeed, another advantage of pu18. Its macrocyclic nature makes it an ideal structural unit for creating larger entities by the supramolecular assembly. This property could be used in cancer treatment and imaging (see Chapter 9), as certain peptide-conjugated pu18 derivatives can create in situ nanofibers and, thus, prolong retention time in tumors and, thus, enable improved imaging opportunities and more effective therapeutical outcome [26]. Therapy with pu18 is, as aforementioned, based mainly on its photosensitivity. This phenomenon is utilized in diverse therapeutical approaches, 
mainly PDT and PTT. Pu18, as well as other PSs, is also able to absorb energy delivered into tumors by ultrasound, which is used in SDT. Both PDT and SDT might be also combined with cancer diagnostics and, thus, pu18 can act as a theranostic agent. In the following chapters, we discuss the basics of all these approaches as well as the potential therapeutic and diagnostic roles of pu18 and its derivatives in cancer.

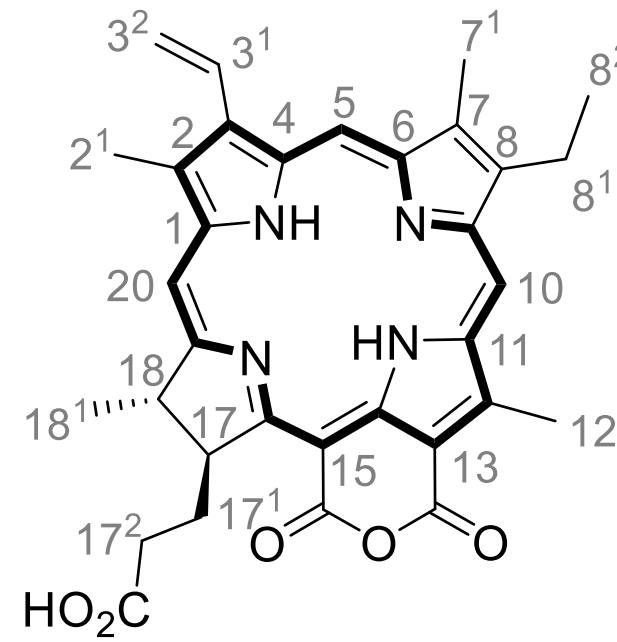

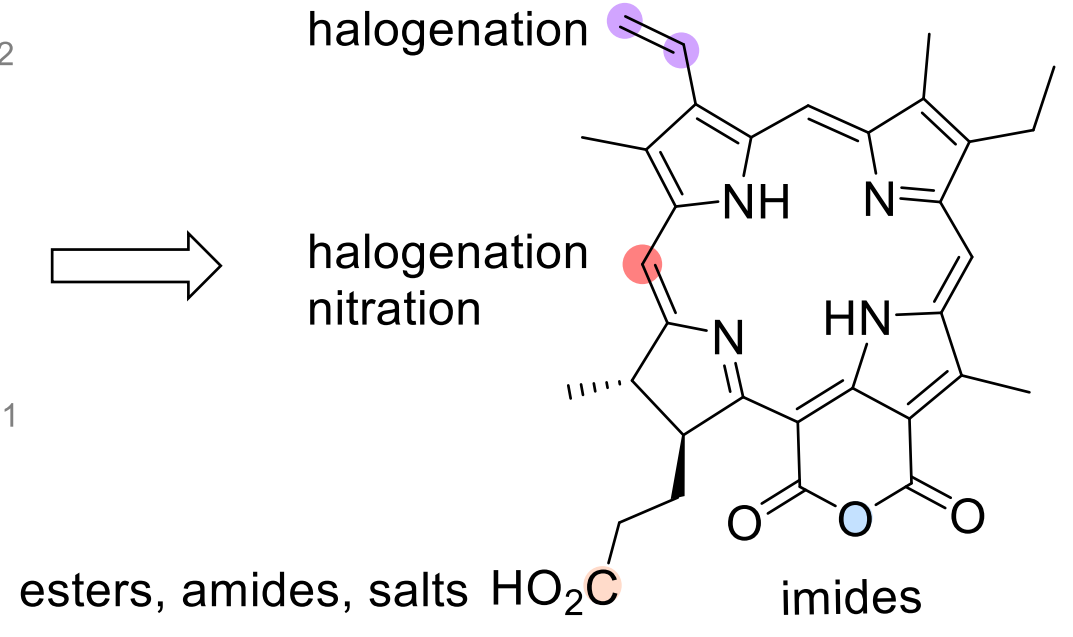

esters, amides, salts $\mathrm{HO}_{2} \mathrm{C}$ imides

Figure 2. Numbered molecular structure of purpurin 18 (pu18) and positions of frequent modifications. The pu18 molecule is usually modified to improve its photochemical properties, for example, by halogenation (violet dots) or nitration (orange dots), or derivatized by conjugation reactions with peptides or other tumor cell-targeting molecules. The most common approaches are the use of a free carboxyl group (C-173) to form esters or amides (an orange dot) or by the derivatization of a cyclic anhydride to form imides (a blue dot).

\section{Photodynamic Therapy}

PDT is an attractive approach to the treatment of many types of cancer and noncancerous diseases. This approach is based on the administration of photoactive substances, so-called PSs, which themselves (without any stimulation) do not exhibit any biological activity. They are activated by illumination with light of appropriate wavelength upon which a PS transits into an excited state. Then, the excited PS can react with molecular oxygen to form ROS and singlet oxygen. The presence of these particles in a cell leads to strong oxidative stress resulting in cell damage and cell death (Figure 3). However, ROS play a dual role in cancer treatment, since they can trigger multiple cellular cascades leading also to pro-tumorigenesis [27]. The ideal PS should meet several criteria, such as high quantum yield of singlet oxygen and absorption in the dark red or near-infrared region of the electromagnetic spectrum $(650-800 \mathrm{~nm})$, which ensures deeper penetration of the light into a treated tissue. On the contrary, negligible absorption of the PS in the visible part electromagnetic spectrum $(400-600 \mathrm{~nm})$ is desirable due to possible photosensitization of the skin [28]. Excitation and emission spectra are very important properties of PSs because human tissue contains many endogenous chromophores that also absorb light. For example, hemoglobin, myoglobin, melanin, and water absorb light in the 600-1000 nm region, which limits the biological window in this range of wavelengths [29]. Therefore, current trend is to develop novel PSs absorbing in the range of the second and third nearinfrared (NIR) region of the electromagnetic spectrum (NIR-II: 1000-1350 nm, NIR-III: $1550-1870 \mathrm{~nm}$ ), which provides the benefit of deeper tissue penetration, enhanced image contrast due to reduced optical scattering, and lower phototoxicity [30]. Related to this, it is another important property of a PS - preferred and ideally selective accumulation of the PS in the target, usually tumor, tissue. Equally important in PDT is none or marginal dark toxicity (without photoactivation) of the PS and its potential metabolites. What makes the use of PDT for cancer treatment more advantageous over conventional surgical methods 
are its low invasiveness and minimal side effects, which are frequently encountered in chemotherapy and radiotherapy. For this reason, PDT has been a very attractive method in cancer treatment.

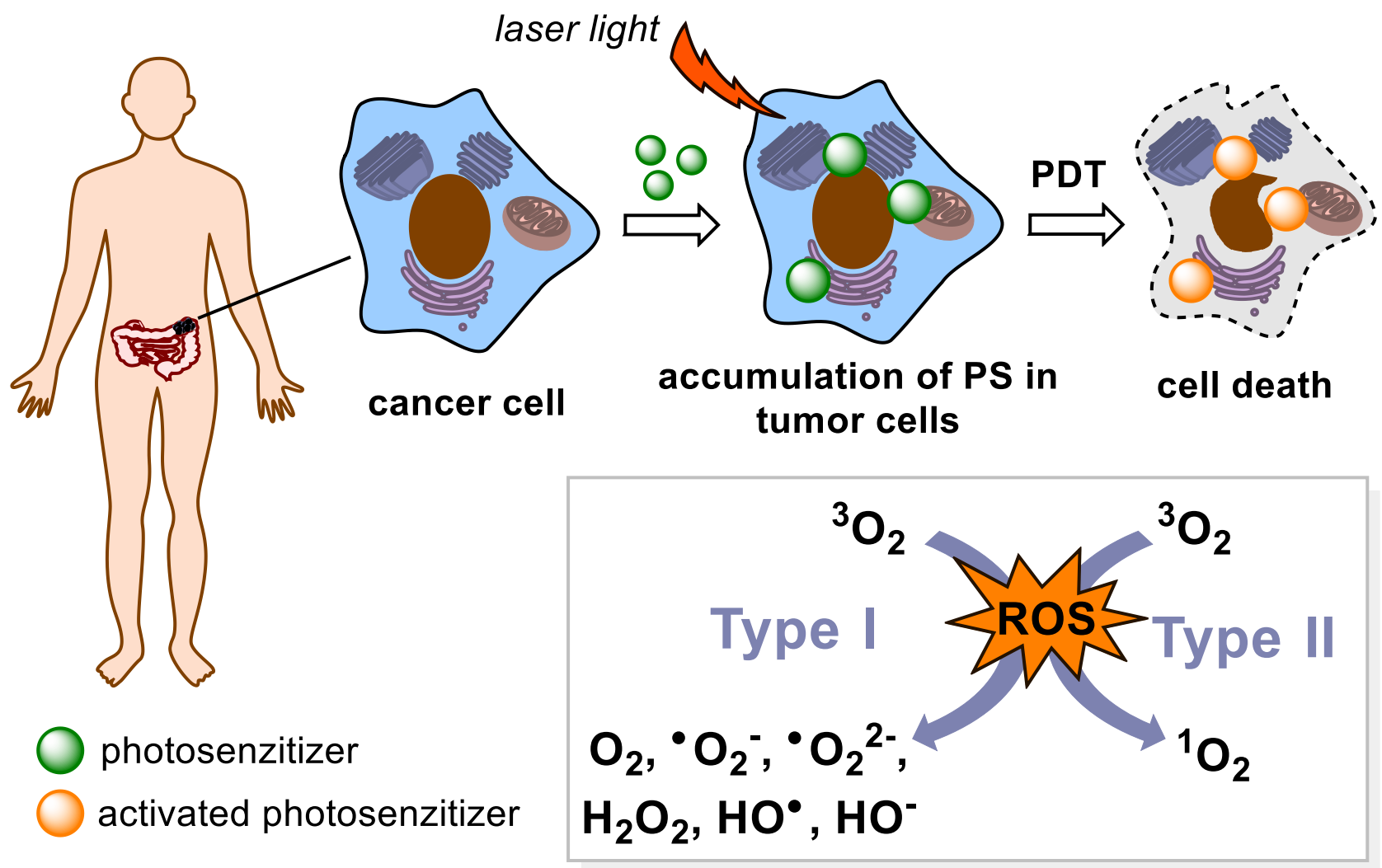

Figure 3. A general principle of photodynamic therapy (PDT). PDT is based on the action of light radiation on a photosensitive drug (PS). After receiving energy, it passes into a higher energy state. Then, it transfers the received energy to surrounding molecules and turns back to its ground state. In the energy transfer mechanism Type I, the energy is transferred to a biomolecule which reacts with ${ }^{3} \mathrm{O}_{2}$ to form reactive oxygen species (ROS). During the Type II transfer, there is a direct reaction of the PS with the ${ }^{3} \mathrm{O}_{2}$ molecule, with the formation of singlet oxygen ${ }^{1} \mathrm{O}_{2}$, which also belongs to the ROS.

In PDT, substances originating in natural products are often used as PSs, including the already mentioned pu18. Pu18 in connection to photoactivation has attracted scientific interest already more than thirty years ago when Hoober et al. [18] discovered that photoactivated pu18 inhibits the growth of primary human fibroblasts. Thirteen years later, after the reports that photoactivated pu18 induces apoptosis and necrosis also in human cancer cells, namely HL-60 (cells from leukemia) [31,32], the real boom in pu18 research related to cancer treatment has started.

More recently, pu18 has been tested as an effective PS for PDT treatment of commonly incurable triple-negative breast cancer [33]. The phototoxicity of pu18 was determined using a mouse mammary tumor cell line (4T1), which is used as a model of stage IV human breast cancer. 4T1 cells were used in the form of two-dimensional (2D) culture, three-dimensional (3D) spheroids, and, also, in vivo in Balb/c mice with subcutaneously implanted $4 \mathrm{~T} 1$ cells. In the case of $4 \mathrm{~T} 12 \mathrm{D}$ cell cultures, significant phototoxicity of pu18 $(0.5 \mu \mathrm{M})$ was observed after light illumination at $630 \mathrm{~nm}\left(35 \mathrm{~s}, 3.71 \mathrm{~J} \cdot \mathrm{cm}^{-2}\right)$. Without photoactivation, pu18 did not exhibit any signs of toxicity up to $4 \mu \mathrm{M}$ concentration. During the microscopic analysis of PDT-treated cells, a change in the cell shape (size reduction, rounding, vacuolation) and their separation from the surface of the culture dish was detected. Flow cytometry analysis showed that PDT treatment of $4 \mathrm{~T} 1$ cells using $0.5 \mu \mathrm{M}$ pu18 $\left(0.724 \mathrm{~J} \cdot \mathrm{cm}^{-2}\right)$ successfully induced apoptosis in $50 \%$ of the cells. For $4 \mathrm{~T} 1$ cells cultured as 3D spheroids, the cells were exposed to $4 \mu \mathrm{M}$ pu18 for $24 \mathrm{~h}$ and were photoactivated at $630 \mathrm{~nm}\left(4 \mathrm{~min}, 25.2 \mathrm{~J} \cdot \mathrm{cm}^{-2}\right)$, 
and further cultured for 6 days. On the second day after PDT, a decrease in the mean of $4 \mathrm{~T} 1$ spheroids was observed compared to the control group. However, further cultivation showed that in the PDT-treated group, cell growth was not completely inhibited, since the 4T1 spheroids were further increasing their volume. However, it was slower than in the case of PDT-untreated 4T1 spheroids. The PDT effect of pu18 administered intratumorally was verified using experimental Balb/c mice with subcutaneously implanted $4 \mathrm{~T} 1$ cells. After PDT treatment (pu18, $0.625 \mathrm{mg} \cdot \mathrm{kg}^{-1}, 600 \mathrm{~J} \cdot \mathrm{cm}^{-2}$ ), the tumor size was monitored every second day for two weeks. Six days after PDT, a significant decrease in the tumor volume $(60 \%)$ was observed in the PDT-treated group compared to control groups, in which a constant growth of the tumors was observed. Although PDT significantly suppressed the size of the tumor, its overall disappearance did not occur here either. However, the survival time of PDT-treated mice was longer compared to the control group. The obtained results indicate a high efficacy of pu18 as a potent PS for the use in PDT. Nevertheless, there are still big weaknesses of high pu18 hydrophobicity (leading to the formation of pu18 aggregates), low bioavailability (difficult delivery of pu18 to a tumor tissue), and rapid removal from the tumor tissue [33]. Researchers have tried to solve these shortcomings by derivatization of the pu18 structure, such as creating imides, or anhydrides [34-37], conjugating it to a molecule of a carrier or creating various types of pu18-containing nanoparticles.

A solution to reduce pu18 hydrophobicity and improve its bioavailability is, for example, conjugation of pu18 with a polyethylene glycol (PEG) spacer, as described in our previous article [38]. It was observed that the newly prepared PEGylated pu18 conjugates efficiently accumulated in human cancer cells of various origins (breast-MCF-7, prostatePC-3 and LNCaP, cervix-HeLa, and pancreas-MiaPaCa-2) in vitro with preferential localization in PDT of important organelles such as mitochondria and endoplasmic reticulum (ER). Attachment of the $\mathrm{PEG}_{3}$ arm also led to an increase in phototoxicity after light illumination $\left(4 \mathrm{~J} \cdot \mathrm{cm}^{-2}, 13 \mathrm{~min}\right)$ compared to the parental compound. The increase in phototoxicity was probably due to the increase in the conjugate hydrophilicity and, thus, improved solubility of the compound in aqueous media. This further led to a reduction in the formation of pu18 aggregates and better drug bioavailability. To increase the PEGylated conjugate modality, it was further modified with a zinc ion which was incorporated into the pu18 structure. The presence of a zinc ion led to an increase in the absorption in the red region of the visible spectrum, which could enable also imaging of this compound.

Besides PEGylation, conjugating of pu18 to biocompatible graphene oxide (GO), has been described. Thanks to its unique surface properties (carboxyl, hydroxyl, and epoxy groups, free $\pi$ electron, $\mathrm{pH}$-dependent negative surface charge), GO can bind drug molecules and, thus, contribute to their efficient transport into tumor cells. The properties of GO as a PS carrier were used in the work of Zhang et al. [39], who prepared GO-Pu18 conjugates composed of GO with non-covalently bound ( $\pi-\pi$ stacking, hydrophobic interactions) pu18 methyl ester, with the aim to increase water solubility, improve bioavailability, control $\mathrm{pH}$-release of pu18 and possibly use in theranostics (see Chapter 9). A similar approach was used by Kang et al. [40], who prepared two types of nanoparticles GO-PS2 and GO-PS3, composed of GO as a carrier and pu18- $\mathrm{N}$-ethylamine as a PS. These nanoparticles differed from each other in the type of bonds in the molecule, GO-PS2 contained covalently bound PS, which led to the high stability of the particles under different conditions. In contrast, GO-PS3 contained, like the aforementioned GO-pu18, non-covalently bound PS, which was released at a slightly acidic $\mathrm{pH}$ (Figure 4A). Based on the microscopic examination, it was found that all prepared conjugates (GO-Pu18, GO-PS2, GO-PS3) are transported into human tumor cells (HepG2, A549) to a greater extent than the unconjugated pu18. Increased phototoxicity of conjugates GO-Pu18 (HepG2 cell line, xenon lamp, $700 \mathrm{~nm}, 5 \mathrm{~mW} \cdot \mathrm{cm}^{-2}, 10 \mathrm{~min}$ ) and GO-PS2, GO-PS3 (A549 cell line, laser, $610-710 \mathrm{~nm}, 2 \mathrm{~J} \cdot \mathrm{cm}^{-2}, 15 \mathrm{~min}$ ) vs. free pu18 after photoactivation was detected. Dark toxicity (without photoactivation) corresponded to a free PS for GO-pu18 and GO-PS2 conjugates. No toxicity was observed for GO-PS3 in the specified concentration range. Although GO-PS3 showed a lower rate of ${ }^{1} \mathrm{O}_{2}$ generation compared to free pu18 (in vitro), higher PDT activity was determined for GO-PS3. This 
was probably due to the more efficient delivery of GO-PS3 to the cells and the release of non-covalently bound pu18- $\mathrm{N}$-ethylamine in the acidic environment of the tumor cells. Both research groups have shown that GO can be a suitable carrier for the efficient delivery of a PS to cancer cells. From the point of view of the targeted release of a PS in tumor tissue, it is advantageous to use noncovalent binding for linking the carrier to the PS molecule.

Currently, great potential in the development of PSs for PDT have nanoparticles. These can be used, for example, for reducing the PS hydrophobicity and to improve its bioavailability. This approach was chosen by Liu et al. [41], who prepared three types of water-soluble organic nanoparticles (WSONs) containing chlorine derivatives such as PS: methyl pyropheophorbide $a$ (MPPa), zinc metal-introduced MPPa (ZnMPPa), and pu18 methyl ester (pu18ME). All prepared WSONs reached a size of 87-112 nm and showed good solubility and stability in water. Fluorescence microscopy analysis showed the entry of all WSONs into human HeLa tumor cells and their localization in mitochondria. High phototoxicity of WSONs after light-emitting diode (LED) illumination was also recorded $\left(640-710 \mathrm{~nm}, 2 \mathrm{~J} \cdot \mathrm{cm}^{-2}, 15 \mathrm{~min}\right)$ which corresponded to the parental PS. The newly prepared WSONs thus preserve or even improve the properties of the original PS, such as absorption in the red region of the visible spectrum, high phototoxicity, and reduced dark toxicity. Besides, the high solubility of WSONs ensures good bioavailability compared to free PS.

Additionally, other research groups have been involved in increasing PS bioavailability. Since gold nanoparticles (GNPs) represent a promising system for pu18 delivery and ensure better entry into tumor cells, recently the group of Lie et al. [42] utilized this tool. They synthesized ionic liquid (IL)-dependent GNPs with pu18 (Figure 4B). This system is based on the properties of water-soluble ILs that can promote increased solubility of conjugated PSs [42]. It has also been reported that ILs can increase drug stability, promote drug delivery, and controlled release [43]. The prepared drugs consisted of IL-type PSs (PS1 = pu18 + morpholinium, PS2 = pu18 + imidazolium), which were incorporated into GNPs (GNP1 contains $492 \mathrm{nmol} \cdot \mathrm{mg}^{-1} \mathrm{PS} 1$ and GNP2 contains $573 \mathrm{nmol} \cdot \mathrm{mg}^{-1} \mathrm{PS} 2$ ) to give 20-60 nm large spherical particles. The phototoxicity of the newly prepared GNP1 and GNP2 was verified using the A549 cell line and illumination with a light-emitting diode $\left(735-785 \mathrm{~nm}, 2 \mathrm{~J} \cdot \mathrm{cm}^{-2}\right.$, $15 \mathrm{~min})$. In the case of GNP1, a 34- and 37-fold increase in phototoxicity was observed compared to free PS1 (12 and $24 \mathrm{~h}$ after photoactivation, constant $\mathrm{IC}_{50}=0.38 \mathrm{~g} \cdot \mathrm{mL}^{-1}$ ) and no observable dark toxicity. Besides, microscopic analysis of GNP1-treated cells in combination with light showed the presence of apoptotic bodies. In contrast, GNP2 showed low phototoxicity at $12 \mathrm{~h}$ after illumination $\left(\mathrm{IC}_{50}>20 \mu \mathrm{g} \cdot \mathrm{mL}^{-1}\right.$ ) and after $24 \mathrm{~h}$, only 3.6 -fold higher phototoxicity $\left(\mathrm{IC}_{50}=4.34 \mu \mathrm{g} \cdot \mathrm{mL}^{-1}\right)$ compared to free PS2. Besides, moderate dark toxicity was determined for both GNP2 and PS2. Thus, it is clear that in the formation of nanoparticles, the type of IL used, and its properties were of great importance. 
A
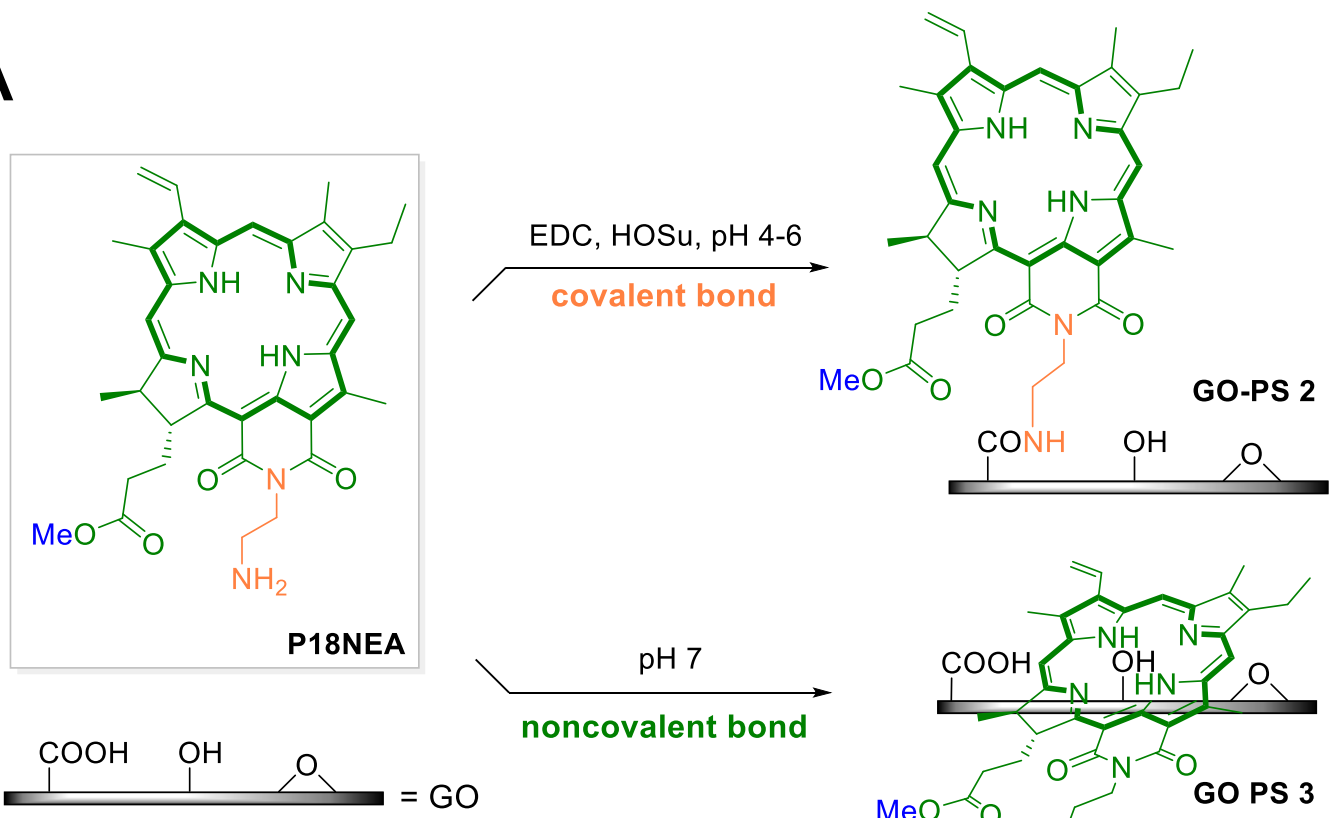

B

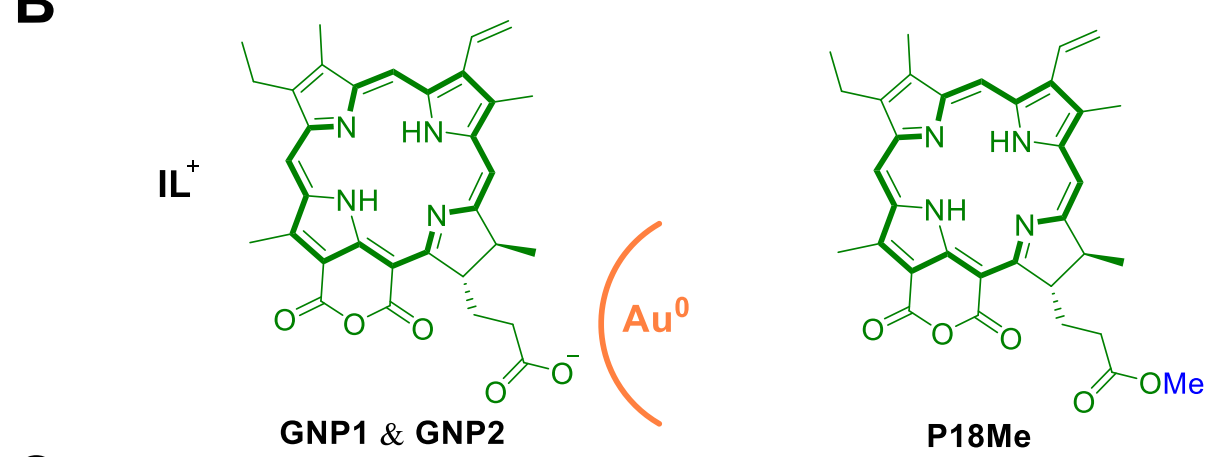

C<smiles>[R][R]O[R]([R])([H])[H]</smiles>

Figure 4. Various types of modifications of purpurin 18 (pu18) may lead to an improvement in its properties as a photosensitizer for use in photodynamic therapy. (A) The first approach is to use a suitable carrier such as graphene oxide (GO) to increase the bioavailability of pu18. In this case, two types of GO nanoparticles were prepared with pu18- $N$ ethylamine (pu18NEA) and a photosensitizer (PS), via covalent (GO-PS2) and non-covalent bonds (GO-PS3). (B) Another type of nanoparticles is based on the properties of ionic liquids (IL), which together with pu18 were incorporated into gold nanoparticles (GNP1 and GNP2) and the structure of pu18-methyl ester (pu18Me). (C) Improved PS retention in tumor cells was observed in the case of conjugated drug pu18 with the amine spermine. In the case of the attachment of a poly(ethylene) glycol (PEG) spacer, an increase in hydrophobicity and an improvement in the bioavailability of PS were observed [44]. 
Nanoparticles can also play an important role in targeted drug delivery to minimize treatment side effects. As an example, $\mathrm{SiO}_{2}$ nanoparticles $\left(\mathrm{SiO}_{2} \mathrm{NPs}\right)$ [45] have several advantages, in particular, nontoxicity and high stability as well as compatibility with various PSs including pu18, chlorine [46], methylene blue [47], and hematoporphyrin [48,49]. The group of Cao et al. used mesenchymal stem cells (MSCs) as pu18 transporters in the form of $\mathrm{PS}-\mathrm{SiO}_{2} \mathrm{NPs}_{\mathrm{s}}$ nanoparticles for targeting breast cancer tumor cells [45]. It is known that MSCs naturally show a high affinity for tumor cells $[50,51]$. The generated $\mathrm{PS}-\mathrm{SiO}_{2} \mathrm{NPs}-\mathrm{MSC}$ particles migrated to human breast cancer cells (MCF-7), which means that the content of PS$\mathrm{SiO}_{2} \mathrm{NPs}$ does not negatively affect the targeting of MSCs and pu18 can thus be accumulated in targeted cells. At the same time, it was found that $\mathrm{PS}_{-} \mathrm{SiO}_{2} \mathrm{NPs}-\mathrm{MSC}$ s inhibited the growth of MCF-7 cells after PDT treatment, both in the form of 2D culture in vitro and in vivo in nude mice with subcutaneously transplanted MCF-7 cells, in which there was a reduction in tumor size and weight. When $\mathrm{PS}-\mathrm{SiO}_{2} \mathrm{NPs}$ were introduced into human embryonic kidney cells (HEK-293) instead of MSCs, no significant PDT effect on cell viability was detected since there was no targeted localization of the drug into the tumor cells [38]. The use of MSCs seems a promising strategy for targeted drug delivery to tumor cells.

A long-term approach in the treatment of cancer is a so-called multimodal therapy which may lead mainly to a reduction in the resistance of tumor cells to anticancer chemotherapeutics. This may be, for example, a combination of tumor resection with chemotherapy, a combination of chemotherapy with PDT, or administration of a multimodal drug. Recently, researchers at Southwest University have developed photo-/chemotherapeutics containing pu18 as a PS [52,53]. The first is a nanogel-based drug (DHP NGs $\sim 67 \mathrm{~nm}$ ) composed of pu18, the chemotherapeutic 10-hydroxycamptothecin (HCPT), a redox responsive cross-linking agent, glutathione responsive spacer, and a PEG spacer to increase particle stability. The second multimodal drug contains doxorubicin (DOX) and pu18 encapsulated in PDP micelles $(\sim 148 \mathrm{~nm})$ composed of mono (6-amino-6-deoxy)- $\beta$-cyclodextrin with a ROS-sensitive polymer containing borate bonds. Both types of drugs have been designed to preferentially accumulate in a tumor tissue based on enhanced permeation and retention effects, for tumor tissue imaging as well as selective drug release due to increased GSH/ROS production by tumor cells. In mouse tumor cell line 4T1, the ability to enter cells, localize in lysosomes and mitochondria, reduce membrane potential of mitochondria and cause cell death has been confirmed [53]. In assays in Balb/c mice implanted with $4 \mathrm{~T} 1$ cells, longer retention time, and better distribution of DHP NGs in tumor tissue compared to free pu18 were detected, as well as a significant reduction of tumor volume after laser exposure $\left(660 \mathrm{~nm}, 0.5 \mathrm{~W} \cdot \mathrm{cm}^{-2}\right.$, $5 \mathrm{~min}$ ). Immunohistochemical analysis of tumor cells subsequently revealed a large number of necrotic and apoptotic cells due to combined photo-/chemotherapy, the treatment did not cause any obvious damage to other organs (the liver, kidneys, heart, and lungs). Very similar results were obtained for the second drug PDP in combination with the same laser treatment. Upon this treatment, only $17.17 \%$ of $4 \mathrm{~T} 1$ cells survived compared to $40.89 \%$ for pure DOX and $61.28 \%$ for pure pu18 in combination with irradiation. Very similar results, as for the first drug, were shown also in experiments on Balb/c mice implanted with 4T1. Both drugs thus represent a significant step in the combined therapy of tumors. A summary of the aforementioned studies on pu18 and its derivatives in PDT is covered in Table 1. 


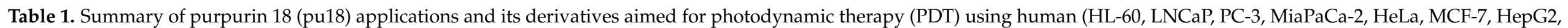

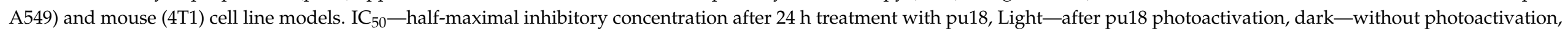
growth inhibition-in studies, where no $\mathrm{IC}_{50}$ was calculated, the compound potency was expressed by percentage of growth inhibition at a certain concentration.

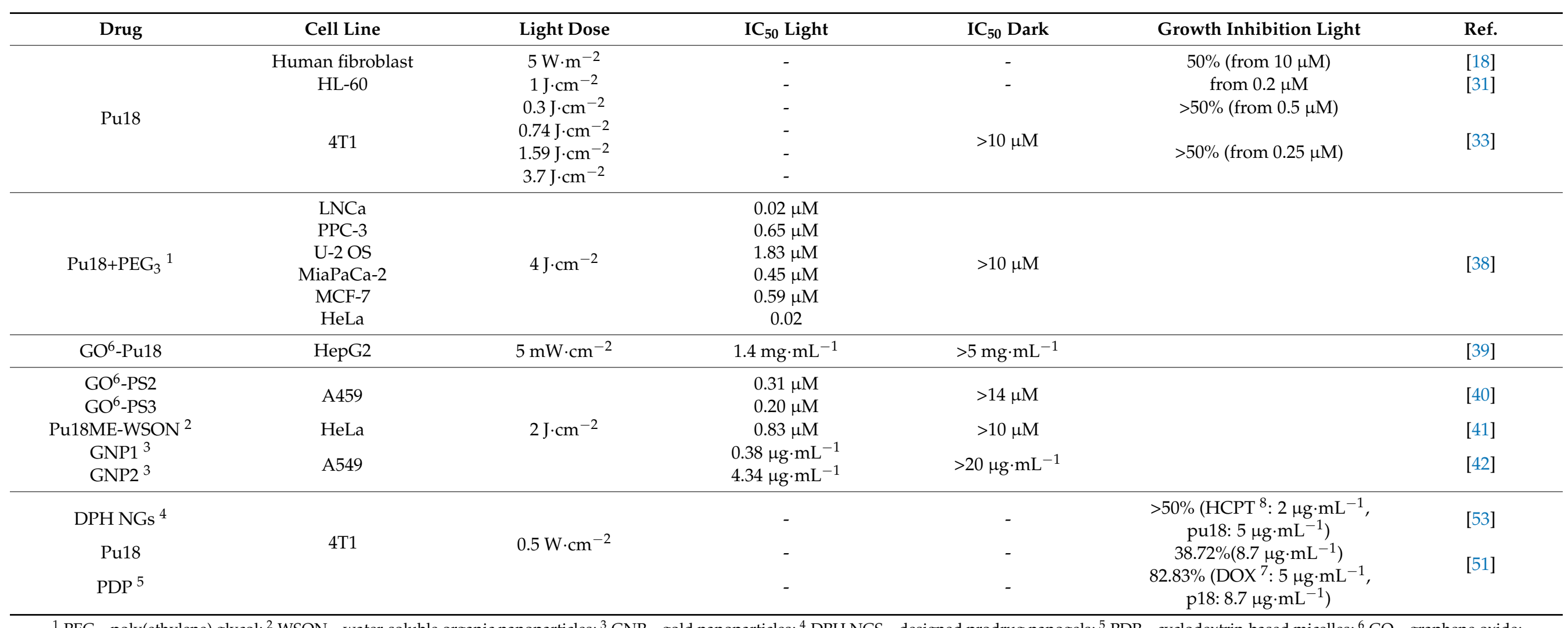

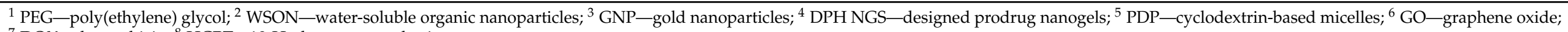

${ }^{7}$ DOX-doxorubicin; ${ }^{8}$ HCPT-10-Hydroxycamptothecin. 


\section{Sonodynamic Therapy and Sonophotodynamic Therapy}

Another noninvasive approach of cancer treatment is sonodynamic therapy (SDT). It is a method discovered and derived based on PDT. In PS evaluation, it was found that, for example, porphyrin [54-57], pheophorbide [57,58], and/or pu18 derivatives [59] used in PDT show similar effects and cell damage after ultrasound application as detected after photoactivation. The main principle of SDT is identical to PDT. The SDT method is based on a combination of low-intensity ultrasound and a sonosensitive agent (ST), which is activated by ultrasound (Figure 5). However, the mechanism of ST activation and ROS formation in SDT is not exactly known. The action of ultrasound generates heat in the target tissue and, also, acoustic cavities. These can occur in two states: stable cavities, which oscillate in an aqueous environment, leading to fluid flow, and inertial cavities, which are characterized by rapid enlargement and subsequent sharp collapse (implosion). During the collapse of these cavities, a large amount of heat $(\geq 5000 \mathrm{~K})$ and pressure $(\geq 800 \mathrm{~atm}$.) is released [60,61]. This can lead to a series of chemical reactions inside, on, or around the collapsing cavitation bubble, which is often referred to as a sonochemical reactor [62]. Typically, pyrolysis or thermal dissociation of water may occur here, which may lead to ST activation and, also, to ROS production.

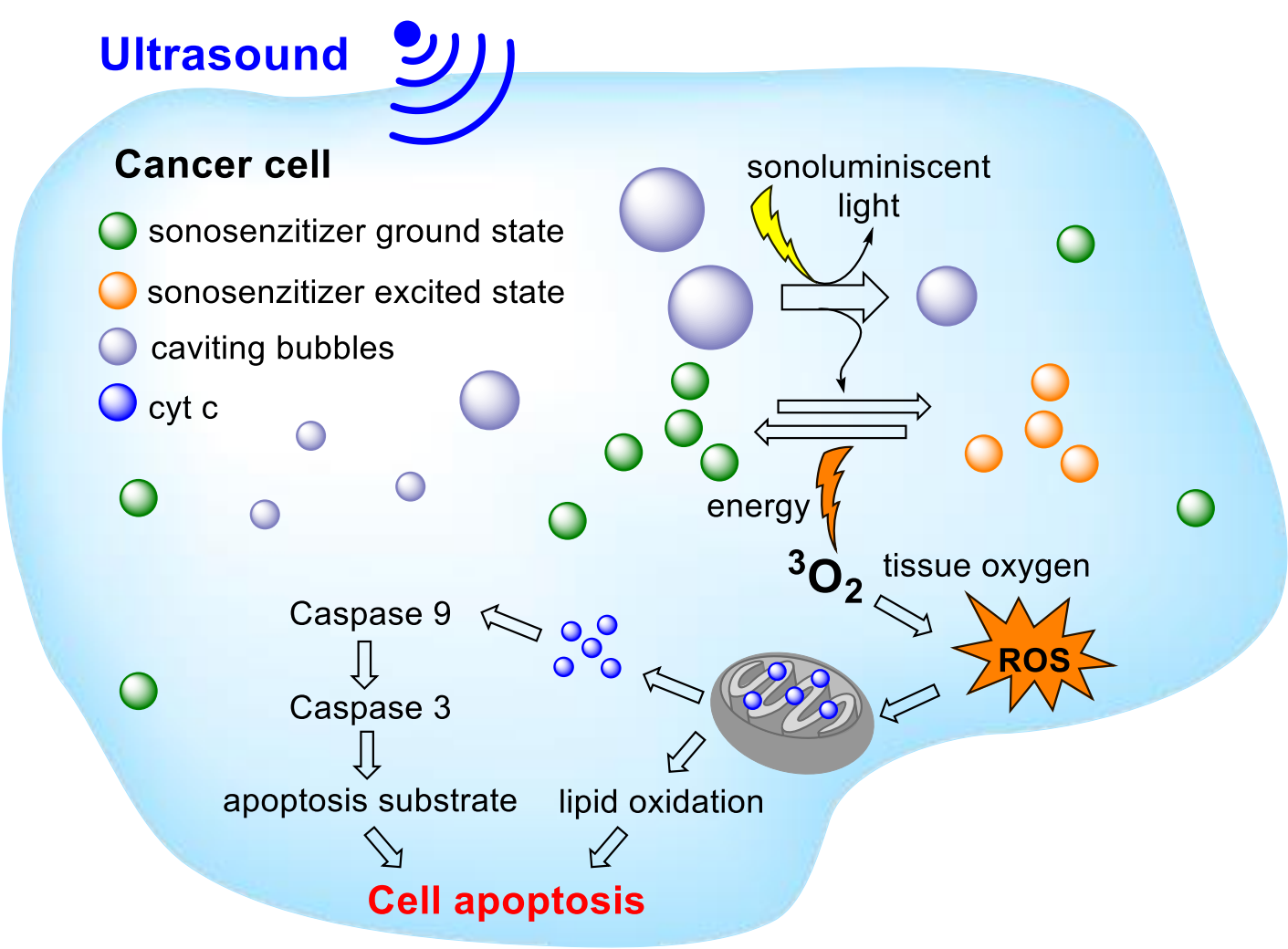

Figure 5. General principles of sonodynamic therapy. The action of ultrasound activates the sonosensitive agent and its transition to a higher energy state. When returning to the basic energy state, the energy generated is transformed in the form of heat, acoustic cavities, or light (sonoluminescence). As a result of these processes, reactive oxygen species (ROS) are formed, which leads to damage of the mitochondrial membrane, the release of cytochrome c (cyt c), and triggering a cascade leading to cell death.

However, some authors suggest that ST activation occurs differently due to sonoluminescence. Sonoluminescence is described as the emission of light that can occur when cavities collapse. This emitted light could thus activate the ST, similarly to that in PDT. However, scientists do not fully agree on this mechanism either [63]. It is, thus, likely that the mechanism of SDT action is a combination of several factors, which depend on the ST and the parameters of the ultrasound used. Although the exact mode of action of SDT 
has not been elucidated, SDT has tremendous potential in the treatment of cancers. An indisputable advantage of SDT over PDT is the deep penetration of ultrasound into soft tissues, which can be even more than $10 \mathrm{~cm}$ [64]. As some PSs can be used as STs, it is possible to combine both approaches as SDT-PDT.

Recently, Shi et al. [65] have described the development of a new tumor-specific and multi-activatable drug called nano-riceball that can be used in SDT. This is a multilayer micelle with a size of $96.8 \mathrm{~nm}$, the core of which is constructed of amphipathic bottlebrushlike dextran-based polymer (DOS), which carries in its structure the anticancer drug DOX and pu18, as a potent ST. This construct is denoted as DDP. For specific tumor cell targeting, the upper layer of the DDP is covered by a bioengineered cell membrane [66], which carries the target motif of the Asn-Gly-Arg (NGR) peptide [67]. It is recognized by various isoforms of the CD13 receptor (aminopeptidase N), which occurs on the membrane of many types of tumor cells and, thus, it is a suitable target for the delivery of anticancer drugs (Figure 6). In this way-targeted drug nano-riceball $\left(\mathrm{NGR}^{\circledR} \mathrm{DDP}\right)$ is preferentially captured on the surface of tumor cells, and is transported into the cells by endocytosis. Shi et al. [68] found that $\mathrm{NGR}^{\circledR}$ DDP accumulates in HepG2 cells within $3 \mathrm{~h}$ of treatment. After sonication of the cells $\left(0.56 \mathrm{~W} \cdot \mathrm{cm}^{-2}, 5 \mathrm{~min}\right)$, there is a rapid increase in ROS, lysosome disintegration, and collapse of the NGR@DDP structure. This leads to a partial release of DOX, then, additional DOX release is achieved by endogenous $\mathrm{H}_{2} \mathrm{O}_{2}$ stimulation. By application of ultrasound, pu18 is also activated, which leads to further ROS generation. Due to the fluorescence of pu18, drug localization can be also monitored. Tests in nude mice with Luc-HepG2 tumors showed preferential accumulation of $\mathrm{NGR}^{\circledR} \mathrm{DDP}$ in tumor tissue as well as significant reduction or complete disappearance of the tumor after administration of $\mathrm{NGR}^{\circledR}$ DDP in combination with an ultrasound. Besides, histological analysis showed extensive tumor tissue damage with minimal damage of normal/healthy tissues, thus suggesting high drug selectivity with the generation of minimal side effects.
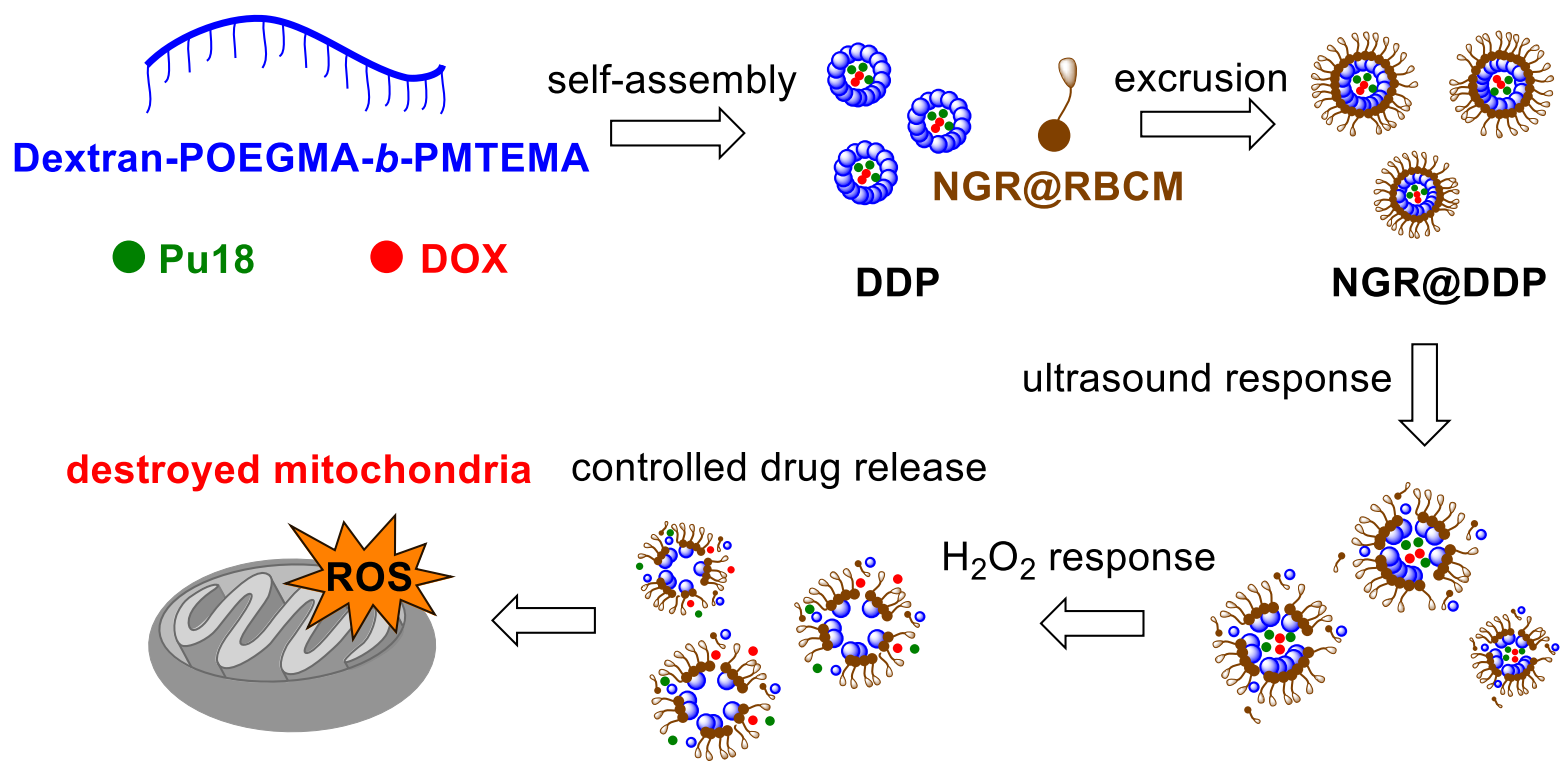

Figure 6. Schematic representation of the preparation of the tumor-specific, mitochondrially targeted, multi-activated (ultrasound $/ \mathrm{H}_{2} \mathrm{O}_{2}$ ) drug NGR ${ }^{\circledR}$ DDP. These are micelles consisting of a universal amphipathic bottlebrush-like polymer dextran-POEGMA-b-PMTEMA, the chemotherapeutic doxorubicin (DOX), and purpurin 18 (pu18), collectively referred to as DDP. These micelles are further coated with a top layer (NGR ${ }^{\circledR} \mathrm{RBCM}$ ) which carries the target motif of the Asn-Gly-Arg (NGR) peptide. POEGMA = poly(oligo ethylene glycol methacrylate); PMTEMA = poly [2-(methylthio)ethyl methacrylate]; $\mathrm{NGR}^{\circledR} \mathrm{RBCM}=$ peptide-labeled red blood cell membrane.

The ST drug PTPK has been developed to image and suppress the growth of pancreatic tumors [68]. Hydrophilic PTPK was prepared in the form of a linear chain composed of the 
cytotoxic peptide Lys-Lys-Leu-Ala-Lys-Leu-Ala-Lys-Lys-Leu-Ala-Lys-Leu-Ala-Lys (KLAKLAK), the ST pu18, and PEG, which is attached by a thiol bond. After PTPK treatment with ultrasound, pu18 is activated to form singlet oxygen, which leads to cleavage of the thiol bond and cleavage of the PEG spacer. The rest of the SH-(pu18) KLAK molecule then forms self-assembled nanoparticles due to increased hydrophobicity. The nanoparticles are then transported into cells by endocytosis (Figure 7). Cytotoxicity assays on the Panc- 1 cell line show that PTPK exhibits higher cytotoxicity and higher mitochondrial damage to treated cells after ultrasound treatment compared to non-cleavable PEG (pu18) KLAK and preprepared (pu18)-KLAK nanoparticles (without PEG). Using a multicellular tumor spheroid of Panc- 1 cancer cells, the ability of single-stranded PTPKs to penetrate deeper into tissues was observed than with pre-packaged (pu18)-KLAK nanoparticles. In situ packaging of nanoparticles is also likely to lead to improved cell transport through endocytosis. Tests on nude mice implanted with Panc-1 cells have shown that PTPK in combination with ultrasound inhibits the growth of subcutaneous and orthotopic tumors.

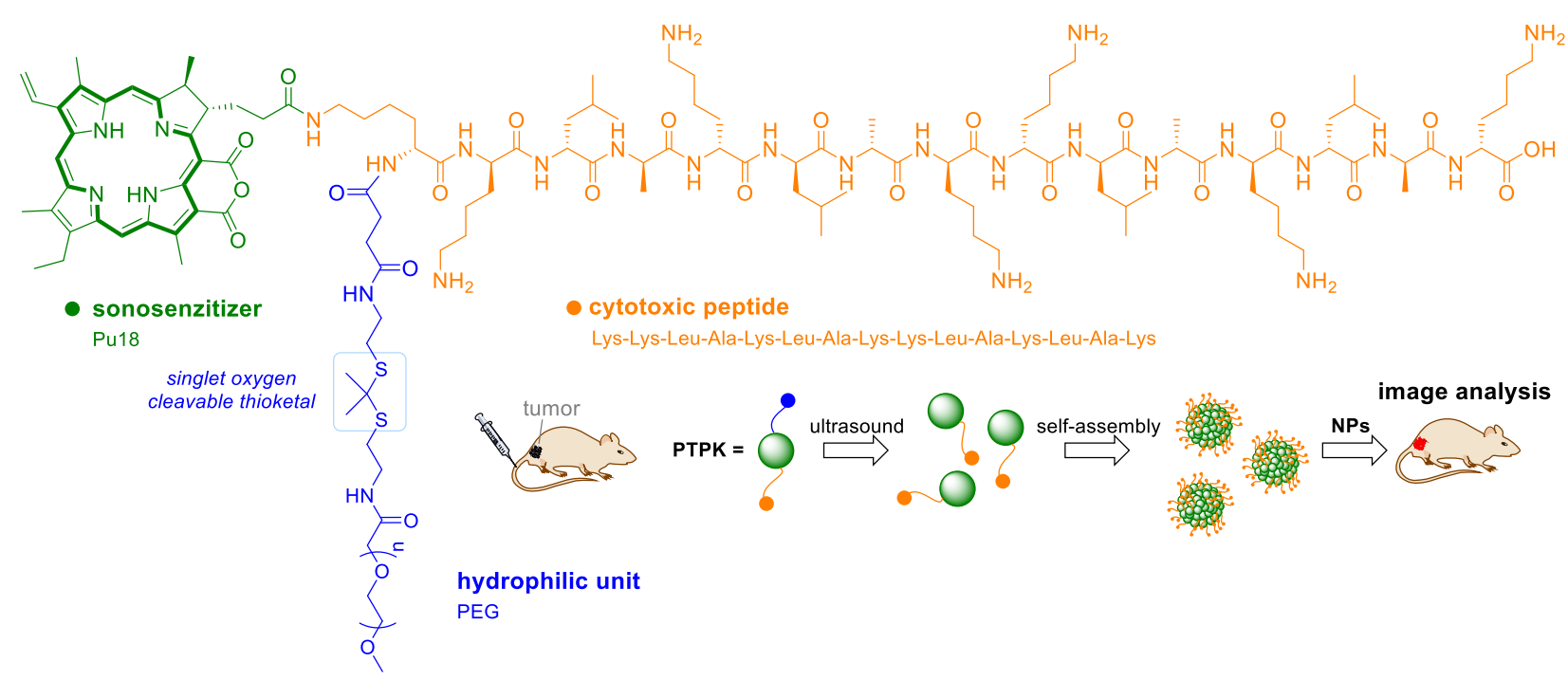

Figure 7. Schematic representation of the ultrasound activatable polypeptide drug PTPK. The drug is applied to the bloodstream in a linear form, pu18 is activated to form singlet oxygen, which leads to cleavage of the thiol bond and disconnection of the PEG spacer. The rest of the molecule then consists of hydrophobic nanoparticles, which can more easily penetrate tumor cells.

\section{Photoacoustic Imaging and Therapy}

Photoacoustic imaging (PAI) is a promising technique for diagnostic and therapeutic purposes in the treatment of cancer due to its high resolution and deep penetration into tissues [69]. In medical applications, photoacoustic imaging is currently in clinical trials for imaging tumors of the breast [70,71], head and neck [72,73], thyroid gland [74], colon, and rectum [75]. The principle of PAI is the generation of acoustic ultrasonic waves based on the conversion of energy supplied by pulsed laser light. If a suitable molecule absorbs light energy, this energy is converted into heat, which also leads to an increase in the temperature around the molecule. Based on the thermoelastic expansion caused by the increase in temperature, ultrasonic waves are subsequently generated, recorded, and analyzed to form an image. Naturally occurring chromophores such as oxy-/deoxyhemoglobin, melanin, or exogenous inorganic and organic substances, which have the potential to absorb energy in the near-infrared region of the spectrum, are used as contrast agents in PAI. Endogenous chromophores can be used in a variety of applications, from brain mapping to monitoring angiogenesis and hypoxia, which are one of the main features of tumor presence. However, their main advantage, i.e., endogenous occurrence, is also their main limitation, due to the difficult distinction between the increased signal vs. the background signal (e.g., in tumor imaging). Some PSs, such as indocyanine green [76], and methylene blue [77] have 
been approved by the US Food and Drug Administration for application in PAI. Besides, due to absorption in long wavelengths, pu18 and its derivatives are also suitable for such application.

For example, it could be beneficial in distinguishing very small tumor features $(<10 \mathrm{~mm})$ from healthy tissues. PAI probes such as pu18/AHC $\subset \mathrm{L}$ (AHC $\subset \mathrm{L}-$ ammonium hydrogen carbonate encapsulated in liposomes) and CD44v6-pu18/AHC $\subset \mathrm{L}$ with improved photoacoustic properties are nanoparticles composed of a lipid bilayer, in which pu18 and $\mathrm{NH}_{4} \mathrm{HCO}_{3}$ aggregates are incorporated [78]. $\mathrm{NH}_{4} \mathrm{HCO}_{3}$ is in the hydrophilic core of the particle (pu18/AHCCL). After laser irradiation of the particles, pu18 aggregates are activated to produce heat and photoacoustic signals (Figure 8). The generated heat $\left(42^{\circ} \mathrm{C}\right)$ further initiates the slow decomposition of $\mathrm{NH}_{4} \mathrm{HCO}_{3}$, which leads to the formation of $\mathrm{CO}_{2}$ bubbles, which significantly contribute to the long-term increase in the photoacoustic signal $(8 \mathrm{~h})$. For targeted imaging of bladder tumors, the surface of the nanoparticles was conjugated to an antibody against the surface protein CD44v6 (CD44v6-pu18/AHC $\subset$ L). This protein has been identified in the colon [79,80], breast [81], and bladder [82] cancer cells, where it is produced to a greater extent than in healthy tissues. The CD44v6 protein is associated with cell migration, adhesion, and tumor metastasis. By comparing the effect of CD44v6-pu18/AHC $\subset \mathrm{L}$ on tumor and healthy human bladder tissue, a preferential accumulation of CD44v6-pu18/AHC $\subset \mathrm{L}$ was found in tumor tissue with a clear tumor delineation. Very small lesions $(<5 \mathrm{~mm})$ were also distinguished, which is a great advantage for early diagnosis of the tumor.

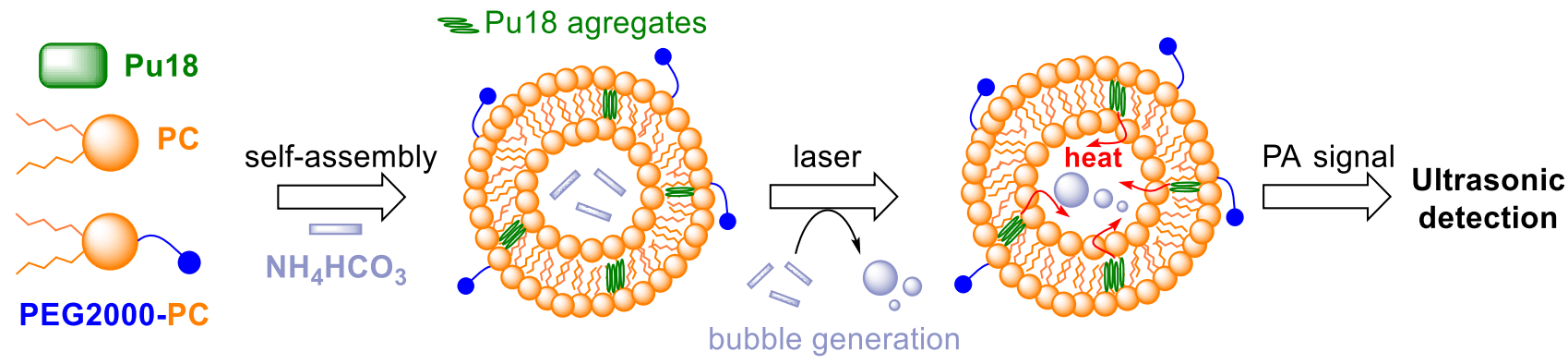

Figure 8. The diagram shows the structure of nanoparticles composed of a lipid bilayer (L- $\alpha$-Phosphatidylcholine $=$ PC, poly(ethylene glycol) $2000=$ PEG2000), in which aggregates of purpurin 18 (pu18) and $\mathrm{NH}_{4} \mathrm{HCO}_{3}$ (in the hydrophilic core of the particle) are incorporated. Under the action of laser irradiation, the pu18 aggregates are activated to produce heat and a photoacoustic (PA) signal. The generated heat activates the slow decomposition of $\mathrm{NH}_{4} \mathrm{HCO}_{3}$, with the formation of $\mathrm{CO}_{2}$ bubbles. This ensures a long-term increase in the PA signal, which can be easily detected for several hours [78].

The problem of the application of not only PAI drugs is bioavailability, which significantly affects the success of the whole process. An attractive approach of the preparation of new bioavailable drugs is the creation of so-called self-assembly molecules. These are usually multifunctional nanostructures that are formed based on van der Waals or electrostatic forces, hydrogen bonds, hydrophobic or $\pi-\pi$ interactions directly in biological systems. This approach was used by Zhang et al. [26] to prepare self-assembled PAI nanofibers that are formed by precursor units. The precursor (pu18-PLGVRGRGD) is composed of pu18 as a PA functional molecule, the enzymatically cleavable peptide chain Pro-Leu-Gly-Val-ArgGly (PLGVRG), and the Arg-Gly-Asp (RGD) sequence targeting $\alpha \mathrm{v} \beta 3$ integrins as tumor cell surface structures. Under the action of the enzyme gelatinase, which occurs in tumor cells, the structure of pu18-PLGVRGRGD is cleaved. The remaining pu18-PLG units subsequently form nanofibers due to intramolecular $\pi-\pi$ interactions (Figure 9). Comparison of the effect of pu18-PLGVRGRGD with a pu18-PLGVRGRDG molecule (without target sequence) on $\alpha \mathrm{v} \beta 3$ overexpressing U87 cells integrates and gelatinizes, confirming the crucial role of the target motif in PA probe accumulation in tumor cells. In mice with implanted U87 cells, the PA signal increased already $2 \mathrm{~h}$ after pu18-PLGVRGRGD application. The highest PA signal was monitored $6 \mathrm{~h}$ after application and a stable PA signal could be 
observed for the next $24 \mathrm{~h}$. Observed PA signal after application of pu18-PLGVRGRGD, range of double values compared to pu18-PLGVRGRDG (no target sequence), indicating increased accumulation of pu18-PLGVRGRGD in the tumor. The formation of nanofibers directly at the tumor site can also lead to a prolongation of the retention time of the probe in the tumor tissue (so-called assembly/aggregation-induced retention). The half-life of pu18-PLGVRGRGD is almost $24 \mathrm{~h}$, which is six times more than in the case of the control probe pu18-PMGMRGRGD with a change in the peptide sequence that is not recognized by gelatinase (does not form nanofibers). In a long-term experiment with U87-xenografted mouse cells, complete tumor disappearance occurred after 23 days of treatment with the pu18-PLGVRGRGD probe in combination with laser treatment. The histopathological analysis did not prove damage to other organs (the heart, liver, kidneys, lungs), while the tumor tissue showed signs of necrosis.

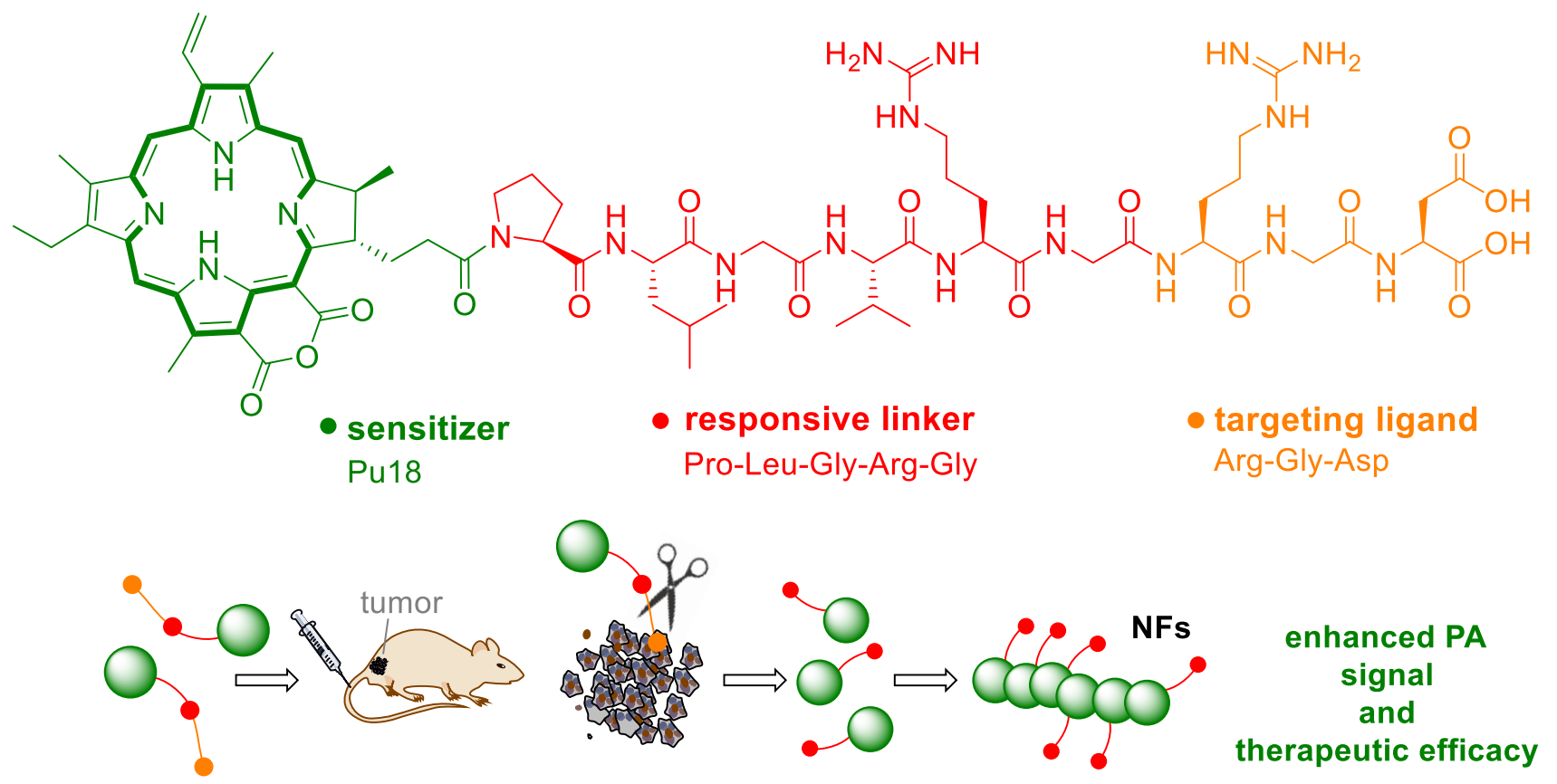

Figure 9. The scheme shows the structure of a prodrug (pu18-PLGVRGRGD) for the preparation of a targeted photoacoustic drug. The pu18-PLGVRGRGD precursor consists of purpurin 18 (pu18), Pro-Leu-Gly-Val-Arg-Gly (PLGVRG) as the enzyme-responsive peptide linker, and Arg-Gly-Asp (RGD) as the targeting ligand. Following application of the monomer precursor, it cleaves at the PLGVRG site in tumor cells. The remaining pu18-PLG units form nanofibers (NFs), which exhibit an enhanced photoacoustic signal [26].

The self-assembly of nanofibers from preformed nanoparticles directly inside cells was an approach used by Zhang et al. [83]. This study was based on the assumption that the formation of nanofibers is dependent on several factors such as concentration of the precursor, ionic strength, and temperature. A transformable polymer-peptide conjugate PKK-S-PEGm was created, which were composed of the cytotoxic peptide KLAKLAK that binds to the mitochondrial membrane, hydrogen-bonding peptide Lys-Leu-Val-Phe-Phe (KLVFF), glutathione-responsive motif disulfide bond linked to PEG chain, and photoacoustic/photothermal molecule pu18 [83]. PKK-S-PEG probes were prepared in the form of 40-nm nanoparticles, which are transported into cells by endocytosis. Upon entry inside the cells, disulfide bridges are cleaved by glutathione, thereby removing the PEG chain stabilizing the spherical structure of the nanoparticle. The nanoparticles are then gradually transformed into nanofibers, which are formed owing to the hydrogen bonds of the KLVFF motif. The morphological change of nanoparticles into nanofibers can be accelerated by laser photoactivation of the particles. Due to the presence of pu18, heat is generated after laser illumination, which accelerates the transformation of nanoparticles into nanofibers 
up to four times (Figure 10). Cytotoxicity assays on the HeLa, MCF-7, and L929 cell lines showed increased cytotoxicity and higher number of apoptotic cells treated with PKK$\mathrm{S}-\mathrm{PEG}$ in combination with laser illumination than in non-illuminated cells. Due to the assay on BALB/c mice transplanted with Hela cells, increased accumulation and retention time of the drug in the tumor tissue was observed. Due to the formation of photoacoustic waves, it was possible to monitor the formation of nanofibers and the movement of the drug in real-time.

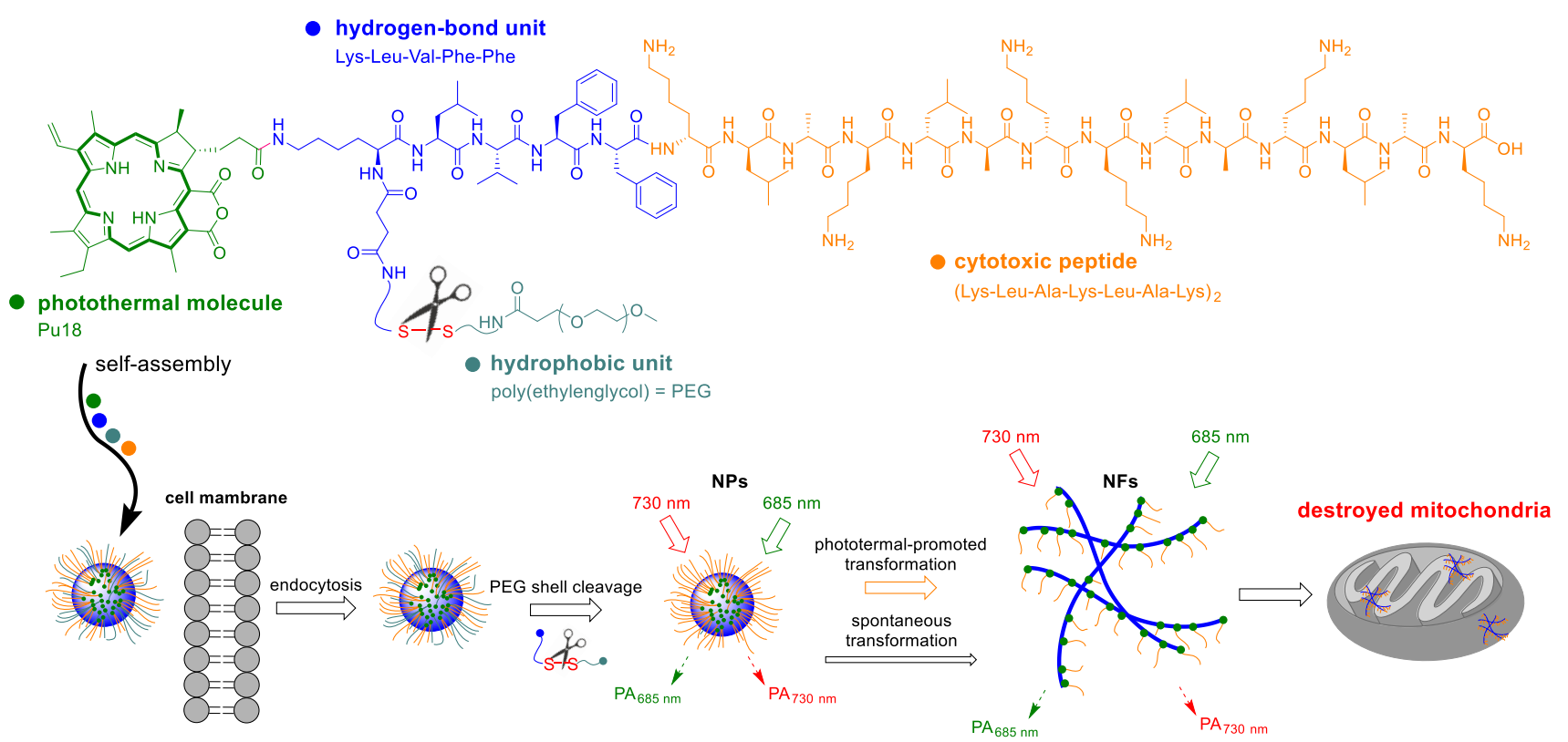

Figure 10. The diagram shows the chemical structure of the polymer-peptide conjugate PKK-S-PEG. It is composed of the cytotoxic peptide Lys-Leu-Ala-Lys-Lu-Ala-Lys (KLAKLAK), which binds to the mitochondrial membrane, a hydrogenbonding peptide motif Lys-Leu-Val-Phe-Phe (KLVFF, originated from the A $\beta$ protein), the hydrophobic unit of poly(ethylene glycol) $=$ PEG, which is attached via a disulfide bridge, and the photoacoustic/photothermal molecule pu18. Drug monomers are spontaneously packaged into nanoparticles, which are transported into cells by endocytosis. Upon entering the cells, the PEG chain is cleaved leading to the spontaneous transformation of nanoparticles (NPs) into mitochondrially targeted nanofibers (NFs). The conversion in NFs can be accelerated photothermally [83].

A similar approach was used by Zhou et al. [25], who studied the properties of selfassembly of molecules composed of pu18 and the amino acid arginine to monitor the aggregation process by PAI in vivo [25]. The prepared derivatives PA1, PA3, and PA7 differed from each other in the number of arginine units $(1,3,7)$, from which the spectral properties, the ability to form aggregates, and the morphology of the formed particles are derived. In the case of monomeric pu18, there was a redshift of the $\mathrm{Q}_{\mathrm{y}}$ band from 700 to $750 \mathrm{~nm}$ during the aggregation process, which indicates the formation of J-type aggregates. At the same time, the fluorescence signal gradually decreased. In the case of monomers PA1, PA3, and PA7, the extinction coefficients (at $700 \mathrm{~nm}$, in dimethylsulfoxide) increased at the same concentration together with the increasing number of arginine units. In an aqueous environment, where conjugates aggregated, higher solubility was observed with a higher number of arginine units leading to less redshift due to hydrophobicity and positive charge of the conjugates. With a higher number of arginine units, a reduced ability to form aggregates and a weak $\pi-\pi$ interaction were also observed for PA7. The same result was shown by the measurement of the fluorescence intensity; in the case of PA1, there was a complete loss of fluorescence, which indicates that all monomers undergo to an aggregated state. In contrast, PA7 showed a similar level of fluorescence in the aqueous medium as in the monomeric state. The fluorescence intensity of PA3 was reduced in the aqueous medium, but it was not completely lost. In aqueous media, both PA3 and PA7 are likely to 
occur in both monomeric and aggregated states. On the contrary, it is known that as the fluorescence signal decreases, the PA signal increases. In connection with the photoacoustic signal, the heat conversion efficiency of the conjugates was studied. A 3-fold increase in heat conversion efficiency was observed for the PA1 and PA3 aggregates compared to their monomeric state. An increase in heat conversion efficiency was also observed for PA7, although not to such an extent. The degree of aggregation of the conjugates in the aqueous medium correlated with heat conversion efficiency, which is proportional to the photoacoustic signal. Zhou et al. [25] also defined the relationship between the degree of aggregation and the relative photoacoustic ratio as a useful tool for aggregation research.

RGD-Dex/NPBA-pu18 (RDNP) monomers were generated to monitor targeted drug delivery, and the structural changes induced by the acidic environment of the cells. By different molar ratios of biocompatible peptide Cys-Gly-Gly-Arg-Gly-Asp (RGD) with dextran (RGD-Dex) as a carrier and a photoacoustic probe pu18 modified with boric acid (NPBA-pu18), a total of five types of monomers (P1-P5) with different properties were prepared. It was found that when NPBA-pu18 is in a 3-fold and higher molar excess over RGD-Dex, RDNP monomers in an aqueous medium can be self-assembled into nanoparticles [84]. The hydrophobic NPBA-pu18 forms a core of nanoparticles that is surrounded by a hydrophilic RGD-Dex. It serves to stabilize the nanoparticle. In an acidic environment, RDNP may cleave due to a pH-dependent phenyl borate bond. The released NPBA-pu18 can repackage into the structure of highly organized nanofibers due to high hydrophobicity and $\pi-\pi$ interactions (Figure 11). After laser irradiation, it is then possible to monitor the PA signal and distinguish the structural changes that are characteristic for the monomeric and aggregated state of NPBA-pu18. P2 (single-stranded) and P5 (nanogranulated) labeled with Cy5 were used for cell entry assays in HeLa cells. Based on the intensity of the fluorescent signal, it was determined that P5 internalized into cells more efficiently than P2 by caveolae-mediated and clathrin-mediated endocytosis. Both conjugates were localized in cell lysosomes/endosomes. 1h after the treatment of HeLa cells with P5, an increasing photoacoustic signal was detected and after $3 \mathrm{~h}$ when all nanoparticles were likely to dissociate to form NPBA-pu18 aggregates, a stable PA signal was achieved. The entire process of structural transformation of RDNP was monitored in real-time using PAI, which makes this method an important tool for following many cell processes, such as targeted drug delivery or autophagy, which is often connected to cancer.

In general, autophagy is a natural catabolic process, in which proteins, organelles, and other cell components are degraded. It is one of the essential cellular processes for maintaining homeostasis, which occurs in response to stressful conditions such as hypoxia, presence of ROS, or lack of nutrients. Some drugs, such as DOX, have been reported to up-regulate autophagy, which can, however, paradoxically lead also to resistance of the cell to chemotherapy $[85,86]$. Therefore, autophagy inhibitors are commonly co-administered with chemotherapeutics to help increase the success of anticancer therapy [87]. However, the combination of these drugs often leads to high systemic toxicity and damage to the organism. Thus, preventive monitoring of autophagy in real time, directly in tumor cells using PAI, could be beneficial. With this goal, Lin et al. [88] developed a novel photoacoustic in vivo self-assembled probe (DDP18, Figure 12). It is composed of hydrophobic pu18 as a signaling molecule, Gly-Lys-Gly-Ser-Phe-Gly-Phe-Thr-Gly (GKGSFGFTG) peptide, the cleavage site of autophagy-related cysteine protease, and poly(amidoamine) dendrimer, which serves as a carrier increasing the solubility and biocompatibility of the molecule. Upon entry of the probe into cells undergoing autophagy, the pu18 residue is enzymatically cleaved with a linker to aid in its folding. 

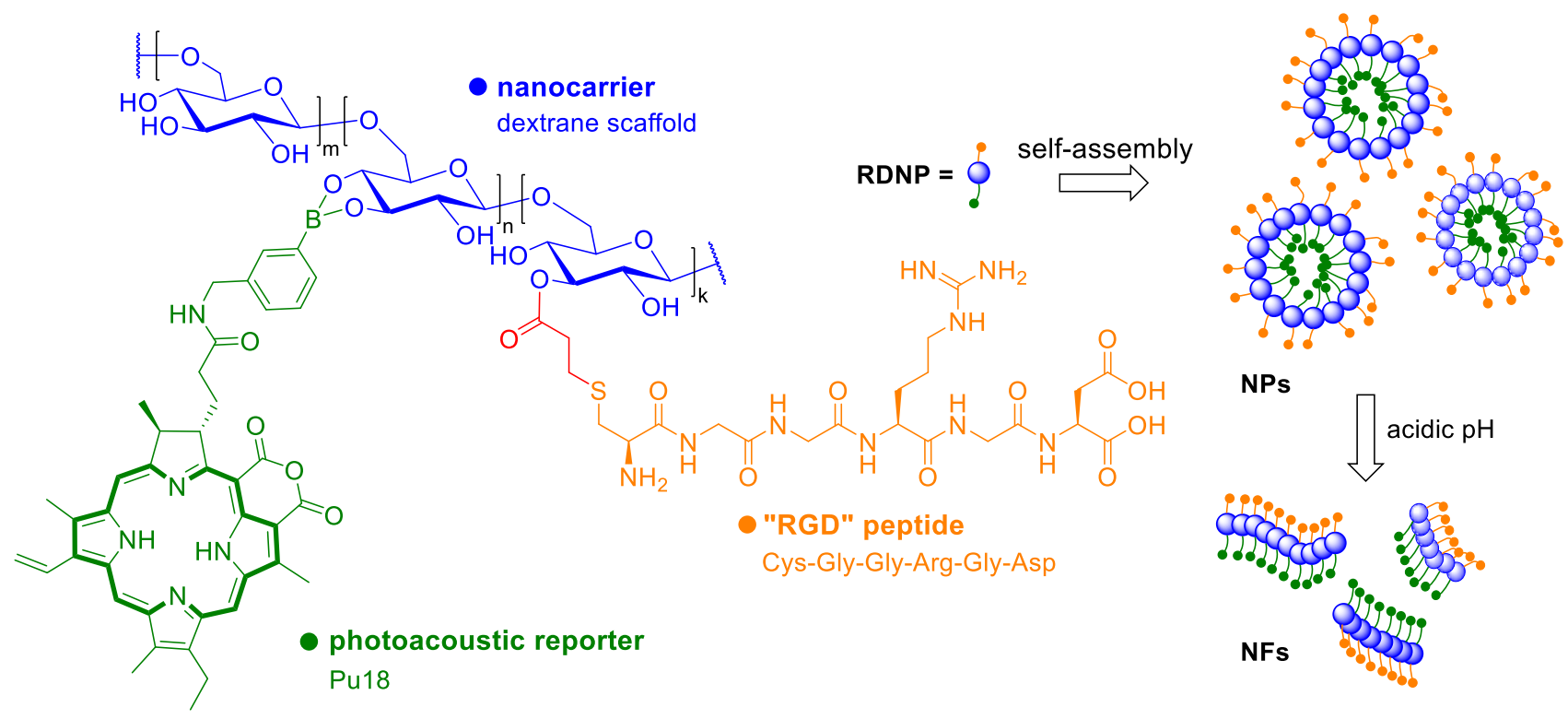

NPs
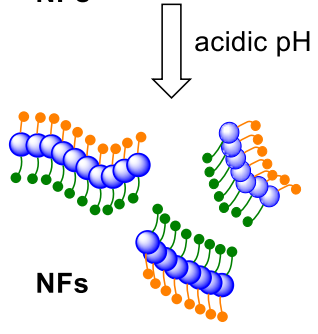

Figure 11. The diagram shows the structure of the photoacoustic drug RDNP. The drug monomers consist of dextran that serves as a carrier, a biocompatible peptide Cys-Gly-Gly-Arg-Gly-Asp (RGD), and a photoacoustic probe pu18, which is modified with boric acid. RDNP monomers spontaneously form nanoparticles (NPs) in an aqueous environment, which can be cleaved to form highly organized nanofibers (NFs) upon transition to the acidic environment of tumor cells. The conversion of NPs to NFs can be monitored in real-time using photoacoustic imaging [84].

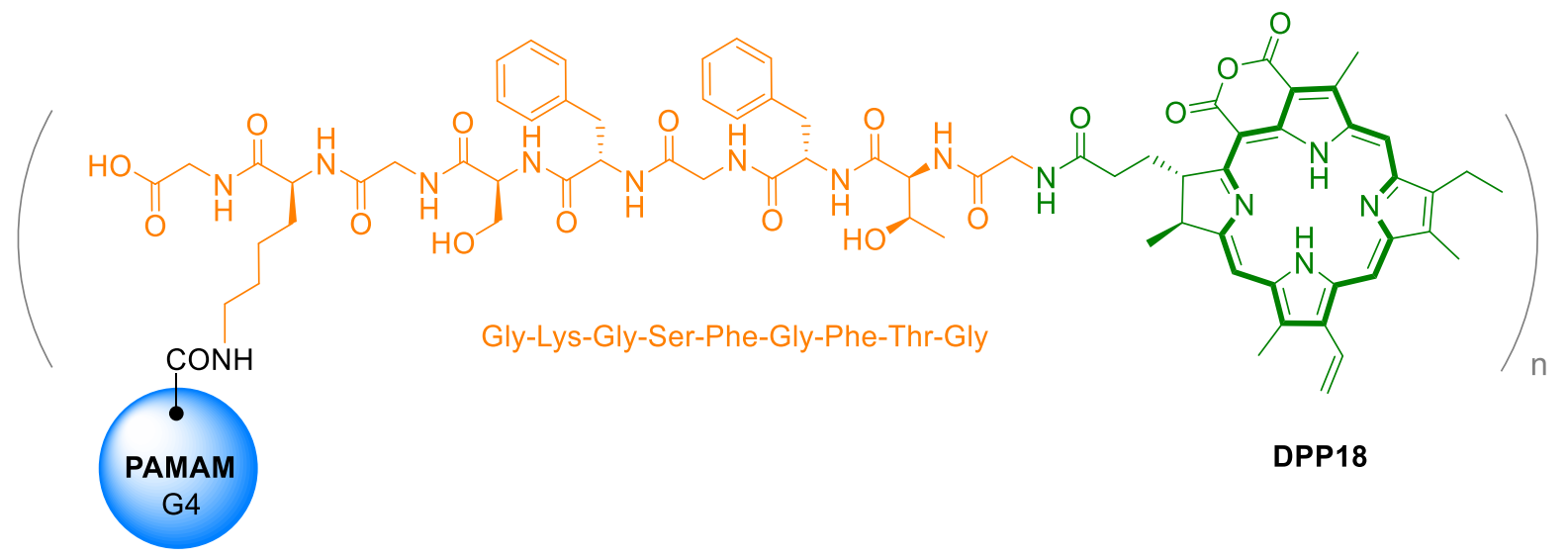

Figure 12. Chemical structure of photoacoustic in vivo self-assembled nanoprobes for imaging and quantitative detection of autophagy. The molecule is composed of poly (amidoamine) dendrimers (PAMAM), the specifically cleavable peptide Gly-Lys-Gly-Ser-Phe-Gly-Phe-Thr-Gly (GKGSFGFTG), and purpurin 18 (pu18) [88].

It has been reported that pu18 in the form of aggregates/nanostructures has a higher photoacoustic response after laser activation than free pu18 due to a change in photothermal conversion capacity [78,89]. Simultaneously with the increase in the PA signal, a decrease in pu18 fluorescence was observed. When verifying the cytotoxic effects in the MCF-7 cell line, very low cytotoxicity was found both without and after laser treatment of the cells under conditions corresponding to PAI $(735 \mathrm{~nm}, 100 \mathrm{~mW}, 10 \mathrm{~s})$, the rate of the photoacoustic signal was also very low (autophagy was not detected). When cells treated with DPP18 were simultaneously treated with an autophagy inducer, a significant increase in photoacoustic signal was measured after laser irradiation. Using DPP18 in vivo in mice, it has been shown that monitoring tumor autophagy with PAI can be successfully used to optimize the dosing schedule of the chemotherapeutic DOX in combination with the autophagy inhibitor hydroxychloroquine. Mice treated with the adjusted dosing regimen showed similar tumor growth suppression as mice treated with the traditional dosing regimen. Besides, however, 
no significant weight loss of the mice or a decrease in white blood cell and platelet counts were observed with the adjusted dose, suggesting an overall better physical condition of the animals. The use of PAI can thus be a promising tool for personalized medicine.

\section{Photothermal Therapy}

The basic component of PTT is, as in the case of PDT, a photosensitive drug molecule that is activated by laser light, usually at near-infrared wavelengths. PTT, however, converts light energy absorbed by a photosensitive drug into thermal energy, which can heat the target tissue to more than $43^{\circ} \mathrm{C}$, leading to DNA damage, denaturation of proteins, and subsequent apoptosis or necrosis. The type of cell death depends on the drug and the type of laser irradiation (laser energy, number of pulses, duration of irradiation) used. As PTT does not require the presence of oxygen in the tissues, it is also suitable for hypoxic tumors, which are often resistant to classical therapy [90]. Nanoparticles of inorganic origin are often used as PTT drugs, including porphyrins, which are usually modified into a nanoparticle structure. However, due to the similarity of PTT and PDT, it is possible to often come across combined drugs that utilize properties of both PTT and PDT to increase the antitumor efficacy. Kim et al. [91] prepared a complex of combined PTT/PDT gold-nanorods (GNR-PS). The formulation is based on GNR composed of hydrogen tetrachloroaurate (III) trihydrate $\left(\mathrm{HAuCl}_{4} \cdot 3 \mathrm{H}_{2} \mathrm{O}\right)$ and cetyltrimethylammonium bromide, which is, however, cytotoxic. For this reason, the layer-by-layer method was used to prepare GNR-PS using cationic poly (allylamine hydrochloride), which suppresses the cytotoxicity of cetyltrimethylammonium bromide and is important for the formation of a dual PTT/PDT system using pu18 as a PS. Verification of the PTT and PDT effects of the GNR-PS drug was performed in A549 cells. After the cell treatment with the GNR-PS, they were photoactivated with a laser (808 $\mathrm{nm}, 120 \mathrm{~J} \cdot \mathrm{cm}^{-2}, 1 \mathrm{~min}$ ) for PTT induction followed by a halogen PDT-inducing lamp (a band-pass filter $640-710 \mathrm{~nm}, 2 \mathrm{~J} \cdot \mathrm{cm}^{-2}, 15 \mathrm{~min}$ ). PTT/PDT-treated cells showed the highest decrease in viability (39\% of viable cells) compared to single therapies (PDT $=90 \%$, PTT $=73 \%$ of viable cells). At the same time, no toxicity of GNR-PS without illumination was observed in the evaluated concentration range $(1-20 \mu \mathrm{M})$. The results also showed that within $1 \mathrm{~min}$ after the PTT, 57\% of the pu18 contained in the GNR-PS was released and without photoactivation only $2 \%$ within $60 \mathrm{~min}$. The combined GNR-PS drug effectively utilizes the synergistic effect of PTT/PDT and is a potent antitumor drug.

\section{Phototeranostic}

The aforementioned methods might all be combined. Moreover, it is possible to combine them with diagnostic tools, which is clinically a very interesting and more and more emerging approach, generally called theranostics. Theranostics represents therapy and diagnosis of a disease covered by a single substance or particle, which, in general, can exhibit very diverse biological activities. The therapeutical part may consist of all possible currently known chemotherapeutics, the structure of which can be modified and linked to the diagnostic part. Diagnosis, in this case, is provided usually by radioactivity or fluorescence of the particular substance. Nevertheless, also other clinical diagnostic tools are being involved, such as magnetic resonance, computer tomography, and others [92]. Pu18 and related derivatives are also being developed for such applications. The advantage of pu18 is the ability to absorb light and emit fluorescence. Once delivered into pathological cells, this ability can be utilized for tumor imaging. Zhang et al. 2018 synthesized pHdependent pu18 loaded GO particles, which were stable at physiological $\mathrm{pH}$, and at low $\mathrm{pH}$, often occurring in tumors, released free pu18. This might be detected by increased fluorescence and, thus, display the tumor. Such particles have also a better ability to yield singlet oxygen $\left(62.6 \%\right.$ quantum yield) compared to free pu18 (58.82\%). In HepG2 cells, $\mathrm{IC}_{50}$ of GO-pu18 after $10 \mathrm{~min}$ of irradiation was $1.39 \pm 0.38 \mu \mathrm{g} \cdot \mathrm{mL}^{-1}$, whereas that of free pu18 was $5.3 \pm 0.79 \mu \mathrm{g} \cdot \mathrm{mL}^{-1}$. The viability of cells without irradiation was higher than $90 \%$ for all the studied concentrations [39]. Generally, pu18 has cytotoxic and fluorescent properties, which makes this compound alone a theranostics agent. Thus, the only question is, how to 
efficiently and specifically deliver this substance to cancer cells and how to preserve its fluorescent and phototoxic properties. The answer might be again proper derivatization. Sun et al. [93] developed a theranostic system consisting of self-assembled nanoparticles (ppu18-lipos) of lipid-pu18 of $2 \mathrm{~mol} \%$ and $65 \mathrm{~mol} \%$ concentrations and pure lipids. The lipid-pu18 derivatives were created by the reaction of pu18 and 1-palmitoyl-2-hydroxy-snglycero-3-phosphocholine. Ppu18-lipos enabled trimodal in vivo imaging by fluorescent and photoacoustic methods and magnetic resonance (Figure 13). The fluorescent signal was observed in vitro more after low-density particle treatment because pu18 in higher concentrations formed aggregates, which caused fluorescence quenching. Photoacoustic signals, on the contrary, increase linearly with pu18-lipid concentrations, since such signals correlate with the thermal expansion of laser irradiated materials. Magnetic resonance signal, which was enabled by treatment with ppu18-lipos- $\mathrm{Mn}^{2+}$ chelates, also increased with ppu18 concentration. A potent therapeutic effect of the ppu18-lipos particles was achieved by PDT and PTT in combination and, also, activation of the immune response was detected after laser irradiation. The synergism of PDT and PTT was followed in vivo in mice bearing $4 \mathrm{~T} 1$ breast tumors. Astonishing $90 \%$ inhibition of tumor growth was achieved with a concentration of ppu18, which was $6 \mathrm{mg} \cdot \mathrm{kg}^{-1}$ lower than that for PDT and PTT alone. Importantly, the advantageous layout of the experiment seems to be a pretreatment of low-density particles and laser activation, because PDT ensures more facile endocytosis of further pu18-lipid particles and subsequently more efficient PTT [93].

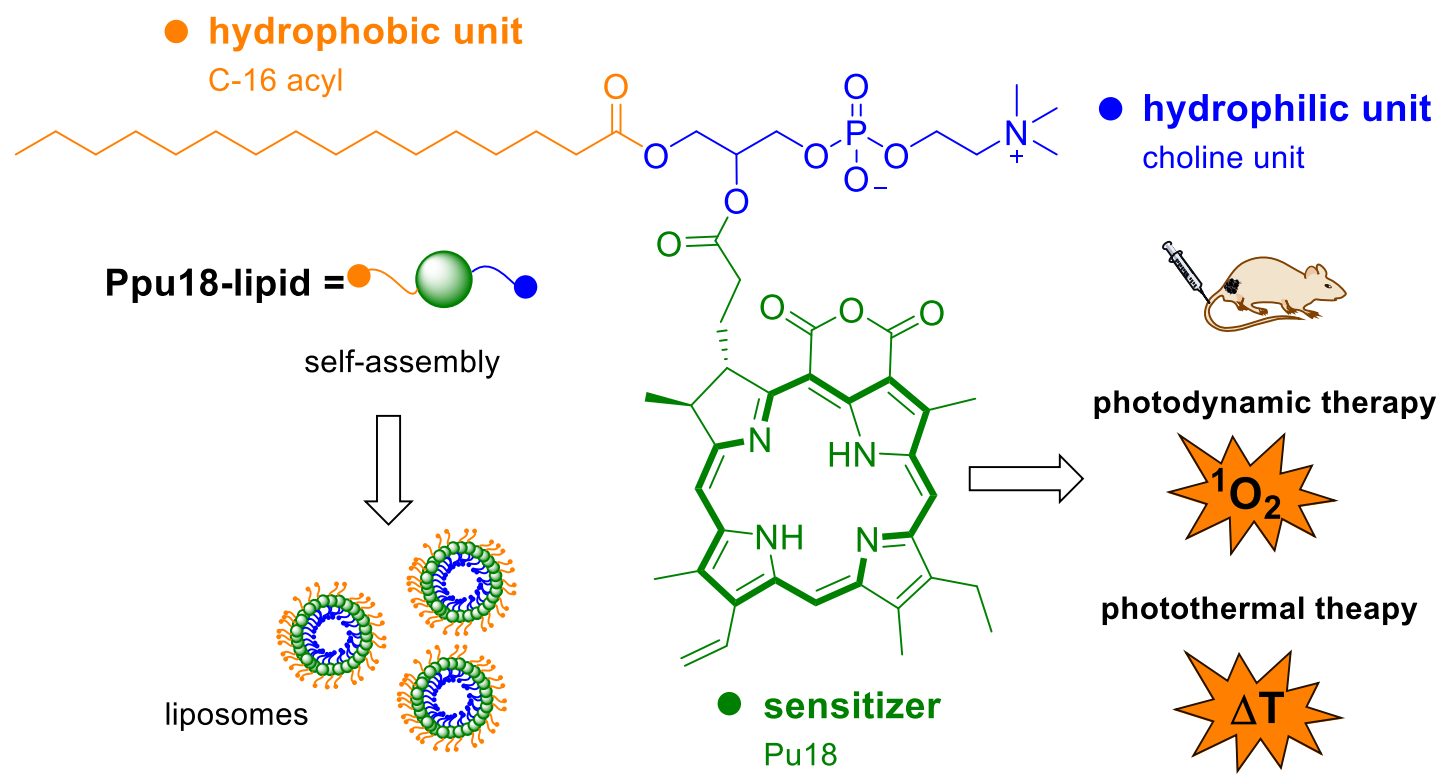

Figure 13. The diagram shows the structure of a combined photodynamic/photothermal drug, which is composed of purpurin 18 (pu18), a hydrophobic part formed by C-16 acyl, and a hydrophilic choline unit. Ppu18-lipid drug monomers form self-assembled liposomes, which can be used as combined theranostics for PDT/fluorescence imaging or PTT/photoacoustic imaging, depending on the amount of pu18 used (mol\%) [93].

\section{Conclusions}

Chlorophyll and its natural metabolites are a very valuable tool in the development of novel anticancer drugs. In particular, one of its metabolites pu18 is a very potent multifunctional molecule that can be used in several anticancer therapies such as PDT, SDT, and PTT, but also in theranostics and tumor imaging for their early diagnosis, e.g., by PAI. All these applications are possible due to the structure of pu18, which allows strong energy absorption and further transfers of this energy leading to the creation of cytotoxic ROS, heat, or fluorescent signal. Another great advantage of pu18 is its low systemic toxicity in the dark environment, thus, causing low side effects during the therapy. Unfortunately, further advancement into clinics is hampered by its low water solubility. However, this problem 
can be easily overcome by its derivatization, which leads to the synthesis of many potent conjugates. Owing to its facile derivatization and unique properties, pu18 represents an effective tool for the development of novel PSs and multimodal drugs, which seem to be the future of anticancer therapy.

Funding: This research was funded by Specific university research MSMT, grant No. A1_FPBT_2020_001.

Institutional Review Board Statement: Not applicable.

Informed Consent Statement: Not applicable.

Data Availability Statement: Not applicable.

Acknowledgments: The authors would like to thank the Applied Sciences journal for providing the APC waiver.

Conflicts of Interest: The authors declare no conflict of interest.

\section{Abbreviations}

2D

3D

$\mathrm{AHC} \subset \mathrm{L}$

Chl

Chla

Chlb

Cyt c

DNA

DOX

DPH NGs

ER

GNPs

GNR

GO

HCPT

$\mathrm{IC}_{50}$

IL

LED

MPPa

MSC

NFs

NIR

PAI

$\mathrm{Pb} a$

PDT

PEG

PMTEMA

POEGMA

PS

PTT

Pu18

Pu18ME

RBCM

RGD-Dex

ROS

SDT

ST

WSONs

ZnMPPa two-dimensional materials three-dimensional materials ammonium hydrogen carbonate encapsulated in liposomes chlorophyll

chlorophyll $a$

chlorophyll $b$

cytochrome $\mathrm{c}$

deoxyribonucleic acid

doxorubicin

well-designed prodrug nanogels

endoplasmic reticulum

gold nanoparticles

gold nanorods

graphene oxide

10-hydroxycamptothecin

half maximal inhibitory concentration

ionic liquid

light-emitting diode

methyl pyropheophorbide

mesenchymal stem cells

nanofibers

near-infrared region

photoacoustic imaging

pheophorbide $a$

photodynamic therapy

polyethylene glycol

poly[2-(methylthio)ethyl methacrylate]

poly(oligoethylene glycol) methacrylate

photosensitizer

photothermal therapy

purpurin 18

purpurin 18 methyl ester

red blood cell memembrane

peptide RGD with dextran

reactive oxygen species

sonodynamic therapy

sonosensitizer

water-soluble organic nanoparticles

zinc metal-introduced methyl pyropheophorbide 


\section{References}

1. World Health Organization. Available online: https:/ / www.who.int/health-topics/cancer\#tab=tab_1 (accessed on 28 December 2020).

2. Hopper, C. Photodynamic therapy: A clinical reality in the treatment of cancer. Lancet Oncol. 2000, 1, 212-219. [CrossRef]

3. Romano, G.; Costantini, M.; Sansone, C.; Lauritano, C.; Ruocco, N.; Ianora, A. Marine microorganisms as a promising and sustainable source of bioactive molecules. Mar. Environ. Res. 2017, 128, 58-69. [CrossRef] [PubMed]

4. Oo, Y.Y.N.; Su, M.C.; Kyaw, K.T. Extraction and determination of chlorophyll content from microalgae. Int. J. Adv. Res. Public 2017, 1, 298-301.

5. Shahidi, F.; Janak Kamil, Y.V.A. Enzymes from fish and aquatic invertebrates and their application in the food industry. Trends Food Sci. Technol. 2001, 12, 435-464. [CrossRef]

6. Pereira, D.M.; Valentão, P.; Andrade, P.B. Marine natural pigments: Chemistry, distribution and analysis. Dyes Pigm. 2014, 111, 124-134. [CrossRef]

7. Pangestuti, R.; Kim, S.K. Biological activities and health benefit effects of natural pigments derived from marine algae. J. Funct. Foods 2011, 3, 255-266. [CrossRef]

8. Holdt, S.L.; Kraan, S. Bioactive compounds in seaweed: Functional food applications and legislation. J. Appl. Phycol. 2011, 23, 543-597. [CrossRef]

9. Khan, S.B.; Kong, C.S.; Kim, J.A.; Kim, S.K. Protective effect of Amphiroa dilatata on ROS induced oxidative damage and MMP expressions in HT1080 cells. Biotechnol. Bioproc. Eng. 2010, 15, 191-198. [CrossRef]

10. Hosikian, A.; Lim, S.; Halim, R.; Danquah, M.K. Chlorophyll extraction from microalgae: A review on the process engineering aspects. Int. J. Chem. Eng. 2010, 2010, 391632. [CrossRef]

11. Manivasagan, P.; Bharathiraja, S.; Moorthy, M.S.; Mondal, S.; Seo, H.; Lee, K.D.; Oh, J. Marine natural pigments as potential sources for therapeutic applications. Crit. Rev. Biotechnol. 2018, 38, 745-761. [CrossRef]

12. Larkum, A.W.D.; Kühl, M. Chlorophyll d: The puzzle resolved. Trends Plant. Sci. 2005, 10, 355-357. [CrossRef] [PubMed]

13. Rüdiger, W. Biosynthesis of chlorophyll $b$ and the chlorophyll cycle. Photosynth. Res. 2002, 74, 187-193. [CrossRef]

14. Tanaka, A.; Tanaka, R. Chlorophyll metabolism. Curr. Opin. Plant. Biol. 2006, 9, 248-255. [CrossRef] [PubMed]

15. Kuai, B.; Chen, J.; Hörtensteiner, S. The biochemistry and molecular biology of chlorophyll breakdown. J. Exp. Bot. 2018, 69, 751-767. [CrossRef] [PubMed]

16. Zvezdanović, J.; Marković, D. Bleaching of chlorophylls by UV irradiation in vitro: The effects on chlorophyll organization in acetone and n-hexane. Serb. Chem. Soc. 2008, 73, 271-282. [CrossRef]

17. Koca, N.; Karadeniz, F.; Burdurlu, S.H. Effect of $\mathrm{pH}$ on chlorophyll degradation and colour loss in blanched green peas. Food Chem. 2007, 100, 609-615. [CrossRef]

18. Hoober, J.K.; Sery, T.W.; Yamamoto, N. Photodynamic sensitizers from chlorophyll: Purpurin-18 and chlorin p6. Photochem. Photobiol. 1988, 48, 579-582. [CrossRef]

19. Drogat, N.; Barrière, M.; Granet, R.; Sol, V.; Krausz, P. High yield preparation of purpurin-18 from Spirulina maxima. Dyes Pigm. 2011, 88, 125-127. [CrossRef]

20. Watanabe, N.; Yamamoto, K.; Ihshikawa, H.; Yagi, A.; Sakata, K.; Brinen, L.S.; Clardy, J. New chlorophyll-a-related compounds isolated as antioxidants from marine bivalves. J. Nat. Prod. 1993, 56, 305-317. [CrossRef]

21. Louda, J.W.; Neto, R.R.; Magalhaes, A.R.M.; Schneider, V.F. Pigment alterations in the brown mussel Perna perna. Comp. Biochem. Physiol. B Biochem. Mol. Biol. 2008, 150, 385-394. [CrossRef]

22. Chen, K.; Ríos, J.J.; Pérez-Gálvez, A.; Roca, M. Comprehensive chlorophyll composition in the main edible seaweeds. Food Chem. 2017, 228, 625-633. [CrossRef] [PubMed]

23. Ocampo, R.; Repeta, D.J. Structural determination of purpurin-18 (as methyl ester) from sedimentary organic matter. Org. Geochem. 1999, 30, 189-193. [CrossRef]

24. Zenkevich, E.; Sagun, E.; Knyukshto, V.; Shulga, A.; Mironov, A.; Efremova, O.; Bonnett, R.; Songca, S.P.; Kassem, M. Photophysical and photochemical properties of potential porphyrin and chlorin photosensitizers for PDT. J. Photochem. Photobiol. B Biol. 1996, 33, 171-180. [CrossRef]

25. Zhou, J.; Gao, Z.J.; Cai, J.Q.; Li, L.L.; Wang, H. Synthesis and self-assembly behavior of chlorophyll derivatives for ratiometric photoacoustic signal optimization. Langmuir 2020, 36, 1559-1568. [CrossRef] [PubMed]

26. Zhang, D.; Qi, G.B.; Zhao, Y.X.; Qiao, S.L.; Yang, C.; Wang, H. In situ formation of nanofibers from purpurin18-peptide conjugates and the assembly induced retention effect in tumor sites. Adv. Mater. 2015, 27, 6125-6130. [CrossRef] [PubMed]

27. Reczek, C.R.; Chandel, N.S. The two faces of reactive oxygen species in cancer. Ann. Rev. Cancer Biol. 2017, 1, 79-98. [CrossRef]

28. Plaetzer, K.; Krammer, B.; Berlanda, J.; Berr, F.; Kiesslich, K. Photophysics and photochemistry of photodynamic therapy: Fundamental aspects. Lasers Med. Sci. 2009, 24, 259-268. [CrossRef]

29. Richards-Kortum, R.; Sevick-Muraca, E. Quantitative optical spectroscopy for tissue diagnosis. Annu. Rev. Phys. Chem. 1996, 47, 555-606. [CrossRef]

30. Hemmer, E.; Benayas, A.; Légaréa, F.; Vetrone, F. Exploiting the biological windows: Current perspectives on fluorescent bioprobes emitting above $1000 \mathrm{~nm}$. Nanoscale Horiz. 2016, 1, 168-184. [CrossRef] [PubMed]

31. Di Stefano, A.; Ettorre, A.; Sbrana, S.; Giovani, C.; Neri, P. Purpurin-18 in combination with light leads to apoptosis or necrosis in HL60 leukemia cells. Photochem. Photobiol. 2001, 73, 290-296. [CrossRef] 
32. Magi, B.; Ettorre, A.; Liberatori, S.; Bini, L.; Andreassi, M.; Frosali, S.; Neri, P.; Pallini, V.; Di Stefano, A. Selectivity of protein carbonylation in the apoptotic response to oxidative stress associated with photodynamic therapy: A cell biochemical and proteomic investigation. Cell Death Differ. 2004, 11, 842-852. [CrossRef]

33. Huang, P.; Zhang, B.; Yuan, Q.; Zhang, X.; Leung, W.; Xu, C. Photodynamic treatment with purpurin 18 effectively inhibits triple negative breast cancer by inducing cell apoptosis. Lasers Med. Sci. 2021, 36, 339-347. [CrossRef] [PubMed]

34. Zheng, G.; Potter, W.R.; SumLin, A.; Dougherty, T.J.; Pandey, R.K. Photosensitizers related to purpurin-18-N-alkylimides: A comparative in vivo tumoricidal ability of ester versus amide functionalities. Bioorg. Med. Chem. Lett. 2000, 10, 123-127. [CrossRef]

35. Wang, J.J.; Yin, Y.F.; Yang, Z. Synthesis of purpurin-18 imide derivatives from chlorophyll- $a$ and- $b$ by modifications and functionalizations along their peripheries. J. Iran. Chem. Soc. 2013, 10, 583-591. [CrossRef]

36. Wipo IP Portal. Available online: https:/ / patentscope.wipo.int/search/en/detail.jsf?docId=WO1995032206 (accessed on 24 February 2021).

37. Lens.org. Available online: https://www.lens.org/lens/patent/US_5591847_A/fulltext (accessed on 24 February 2021).

38. Pavličcková, V.; Rimpelová, S.; Jurášek, M.; Záruba, K.; Fähnrich, J.; Křŕžová, I.; Bejček, J.; Rottnerová, Z.; Spiwok, V.; Drašar, P.; et al. PEGylated purpurin 18 with improved solubility: Potent compounds for photodynamic therapy of cancer. Molecules 2019, 24, 4477. [CrossRef] [PubMed]

39. Zhang, Y.; Zhang, H.; Wang, Z.; Jin, Y. pH-Sensitive graphene oxide conjugate purpurin-18 methyl ester photosensitizer nanocomplex in photodynamic therapy. New J. Chem. 2018, 42, 13272-13284. [CrossRef]

40. Kang, E.S.; Lee, T.H.; Liu, Y.; Han, K.H.; Lee, W.K.; Yoon, I. Graphene oxide nanoparticles having long wavelength absorbing chlorins for highly-enhanced photodynamic therapy with reduced dark toxicity. Int. J. Mol. Sci. 2019, 20, 4344. [CrossRef]

41. Liu, Y.; Lee, T.H.; Lee, S.H.; Li, J.; Lee, W.K.; Yoon, I. Mitochondria-targeted water-soluble organic nanoparticles of chlorin derivatives for biocompatible photodynamic therapy. ChemNanoMat 2020, 6, 610-617. [CrossRef]

42. Liu, Y.; Lee, S.H.; Lee, W.K.; Yoon, I. Ionic liquid-dependent gold nanoparticles of purpurin-18 for cellular imaging and photodynamic therapy in vitro. Bull. Korean Chem. Soc. 2020, 41, 230-233. [CrossRef]

43. Adawiyah, N.; Moniruzzaman, M.; Hawatulaila, S.; Goto, M. Ionic liquids as a potential tool for drug delivery systems. Med. Chem. Commun. 2016, 7, 1881-1897. [CrossRef]

44. Darmostuk, M.; Jurášek, M.; Lengyel, K.; Zelenka, J.; RumLová, M.; Drašar, P.; RumL, T. Conjugation of chlorins with spermine enhances phototoxicity to cancer cells in vitro. J. Photochem. Photobiol. B Biol. 2017, 168, 175-184. [CrossRef] [PubMed]

45. Cao, B.; Yang, M.; Zhu, Y.; Qu, X.; Mao, C. Stem cells loaded with nanoparticles as a drug carrier for in vivo breast cancer therapy. Adv. Mater. 2014, 26, 4627-4631. [CrossRef]

46. Bechet, D.; Auger, F.; Couleaud, P.; Marty, E.; Ravasi, L.; Durieux, N.; Bonnet, C.; Plénat, F.; Frochot, C.; Mordon, S.; et al. Multifunctional ultrasmall nanoplatforms for vascular-targeted interstitial photodynamic therapy of brain tumors guided by real-time MRI. Nanomedicine 2015, 11, 657-670. [CrossRef] [PubMed]

47. Rai, P.; Mallidi, S.; Zheng, X.; Rahmanzadeh, R.; Mir, Y.; Elrington, S.; Khurshid, A.; Hasan, T. Development and applications of photo-triggered theranostic agents. Adv. Drug Deliv. Rev. 2010, 62, 1094-1124. [CrossRef]

48. Lustig, R.A.; Vogl, T.J.; Fromm, D.; Cuenca, R.; Hsi, A.; D’Cruz, A.K.; Krajina, Z.; Turić, M.; Singhal, A.; Chen, J.C. A multicenter phase I safety study of intratumoral photoactivation of talaporfin sodium in patients with refractory solid tumors. Cancer 2003, 98, 1767-1771. [CrossRef] [PubMed]

49. Chen, J.; Keltner, L.; Christophersen, J.; Zheng, F.; Krouse, M.; Singhal, A.; Wang, S. New technology for deep light distribution in tissue for phototherapy. Cancer J. 2002, 8, 154-163. [CrossRef]

50. Kidd, S.; Spaeth, E.; Dembinski, J.L.; Dietrich, M.; Watson, K.; Klopp, A.; Battula, V.L.; Weil, M.; Andreeff, M.; Marini, F.C. Direct evidence of mesenchymal stem cell tropism for tumor and wounding microenvironments using in vivo bioluminescent imaging. Stem Cells 2009, 27, 2614-2623. [CrossRef] [PubMed]

51. Ren, Y.J.; Zhang, H.; Huang, H.; Wang, X.M.; Zhou, Z.Y.; Cui, F.Z.; An, Y.H. In vitro behavior of neural stem cells in response to different chemical functional groups. Biomaterials 2009, 30, 1036-1044. [CrossRef]

52. Ma, X.; Zhang, T.; Qiu, W.; Liang, M.; Gao, Y.; Xue, P.; Kang, Y.; Xu, Z. Bioresponsive prodrug nanogel-based polycondensate strategy deepens tumor penetration and potentiates oxidative stress. Chem. Eng. J. 2020, 127657. [CrossRef]

53. Jia, D.; Ma, X.; Lu, Y.; Li, X.; Hou, S.; Gao, Y.; Xue, P.; Kang, Y.; Xu, Z. ROS-responsive cyclodextrin nanoplatform for combined photodynamic therapy and chemotherapy of cancer. Chin. Chem. Lett. 2020. [CrossRef]

54. Yumita, N.; Nishigaki, R.; Umemura, K.; Umemura, S. Hematoporphyrin as a sensitizer of cell-damaging effect of ultrasound. Jpn. J. Cancer Res. 1989, 80, 219-222. [CrossRef] [PubMed]

55. Yumita, N.; Nishigaki, R.; Umemura, S. Sonodynamically induced antitumor effect of photofrin II on colon 26 carcinoma. J. Cancer Res. Clin. Oncol. 2000, 126, 601-606. [CrossRef] [PubMed]

56. Endo, S.; Kudo, N.; Yamaguchi, S.; Sumiyoshi, K.; Motegi, H.; Kobayashi, H.; Terasaka, S.; Houkin, K. Porphyrin derivativesmediated sonodynamic therapy for malignant gliomas in vitro. Ultrasound Med. Biol. 2015, 41, 2458-2465. [CrossRef] [PubMed]

57. Jin, Z.H.; Miyoshi, N.; Ishiguro, K.; Umemura, S.; Kawabata, K.; Yumita, N.; Sakata, I.; Takaoka, K.; Udagawa, T.; Nakajima, S.; et al. Combination effect of photodynamic and sonodynamic therapy on experimental skin squamous cell carcinoma in $\mathrm{C}_{3} \mathrm{H} / \mathrm{HeN}$ mice. J. Dermatol. 2000, 27, 294-306. [CrossRef]

58. Umemura, K.; Yumita, N.; Nishigaki, R.; Umemura, S. Sonodynamically induced antitumor effect of pheophorbide a. Cancer Lett. 1996, 102, 151-157. [CrossRef] 
59. Singh, P.; Pandit, S.; Mokkapati, V.R.S.S.; Garg, A.; Ravikumar, V.; Mijakovic, I. Gold nanoparticles in diagnostics and therapeutics for human cancer. Int. J. Mol. Sci. 2018, 19, 1979. [CrossRef]

60. Rosenthal, I.; Sostaric, J.Z.; Riesz, P. Sonodynamic therapy-a review of synergistic effects of drugs and ultrasound. Ultrason Snochem. 2004, 11, 349-363. [CrossRef]

61. Canavese, G.; Ancona, A.; Racca, L.; Canta, M.; Dumontel, B.; Barbaresco, F.; Limongi, T.; Cauda, V. Nanoparticle-assisted ultrasound: A special focus on sonodynamic therapy against cancer. Chem. Eng. J. 2018, 340, 155-172. [CrossRef]

62. Mišík, V.; Riesz, P. Free radical intermediates in sonodynamic therapy. Ann. N. Y. Acad. Sci. 2000, 899, 335-348. [CrossRef]

63. McHale, A.P.; Callan, J.F.; Nomikou, N.; Fowley, C.; Callan, B. Sonodynamic therapy: Concept, mechanism and application to cancer treatment. In Therapeutic Ultrasound. Advances in Experimental Medicine and Biology; Escoffre, J.M., Bouakaz, A., Eds.; Springer International Publishing: Cham, Switzerland, 2016; Volume 880, pp. 429-450. ISBN 978-3-319-22536-4. [CrossRef]

64. Zhou, Y.; Wang, D.; Zhang, Y.; Chitgupi, U.; Geng, J.; Wang, Y.; Zhang, Y.; Cook, T.R.; Xia, J.; Lovell, J.F. A phosphorus phthalocyanine formulation with intense absorbance at $1000 \mathrm{~nm}$ for deep optical imaging. Theranostics 2016, 6, 688-697. [CrossRef]

65. Shi, X.; Zhang, Y.; Tian, Y.; Xu, S.; Ren, E.; Bai, S.; Chen, X.; Chu, C.; Xu, Z.; Liu, G. Multi-responsive bottlebrush-like unimolecules self-assembled nano-riceball for synergistic sono-chemotherapy. Small Methods 2020, 2000416. [CrossRef]

66. Enyedi, K.N.; Tóth, S.; Szakács, G.; Mező, G. NGR-peptide-drug conjugates with dual targeting properties. PLoS ONE 2017, 12, e0178632. [CrossRef]

67. Sun, Q.; Wu, J.; Jin, L.; Hong, L.; Wang, F.; Mao, Z.; Wu, M. Cancer cell membrane-coated gold nanorods for photothermal therapy and radiotherapy on oral squamous cancer. J. Mater. Chem. B 2020, 8, 7253-7263. [CrossRef] [PubMed]

68. Cheng, D.B.; Zhang, X.H.; Chen, Y.; Chen, H.; Qiao, Z.Y.; Wang, H. Ultrasound-activated cascade effect for synergistic orthotopic pancreatic cancer therapy. iScience 2020, 23, 101144. [CrossRef]

69. Attia, A.B.E.; Balasundaram, G.; Moothanchery, M.; Dinish, U.S.; Bi, R.; Ntziachristos, V.; Olivo, M. A review of clinical photoacoustic imaging: Current and future trends. Photoacoustics 2019, 16, 100144. [CrossRef]

70. Clinical Trials. Available online: https://clinicaltrials.gov/ct2/show/NCT03897270 (accessed on 28 December 2020).

71. Clinical Trials. Available online: https: / clinicaltrials.gov $/$ ct $2 /$ show $/$ NCT04428528?term $=$ photoacoustic\&cond=Cancer\&draw $=$ 2\&rank=8 (accessed on 28 December 2020).

72. Clinical Trials. Available online: https: / clinicaltrials.gov/ct2/show $/$ NCT04110249?term=NCT04110249\&draw=2\&rank=1 (accessed on 28 December 2020).

73. Available online: https:/ / clinicaltrials.gov/ct2/ show / NCT04437030?term=photoacoustic\&cond=Cancer\&draw=2\&rank=9 (accessed on 28 December 2020).

74. Clinical Trials. Available online: https: / clinicaltrials.gov/ct2/show $/$ NCT04248166?term $=$ photoacoustic\&cond=Cancer\&draw= 2\&rank=1 (accessed on 28 December 2020).

75. Clinical Trials. Available online: https: / / clinicaltrials.gov/ct2/show /NCT04339374?term=photoacoustic\&cond=Cancer\&draw= 2\&rank $=6$ (accessed on 28 December 2020).

76. Kim, C.; Song, K.H.; Gao, F.; Wang, L.V. Sentinel lymph nodes and lymphatic vessels: Noninvasive dual-modality in vivo mapping by using indocyanine green in rats-volumetric spectroscopic photoacoustic imaging and planar fluorescence imaging. Radiology 2010, 255, 442-450. [CrossRef]

77. Song, K.H.; Stein, E.W.; Margenthaler, J.A.; Wang, L.V. Noninvasive photoacoustic identification of sentinel lymph nodes containing methylene blue in vivo in a rat model. J. Biomed. Opt. 2008, 13, 054033. [CrossRef]

78. Zhang, D.; Wang, Z.; Wang, L.; Wang, Z.; Wang, H.; Li, G.; Qiao, Z.Y.; Xu, W.; Wang, H. High-performance identification of human bladder cancer using a signal self-amplifiable photoacoustic nanoprobe. ACS Appl. Mater. Interfaces 2018, 10, 28331-28339. [CrossRef]

79. Zhao, L.H.; Lin, Q.L.; Wei, J.; Huai, Y.L.; Wang, K.J.; Yan, H.Y. CD44v6 expression in patients with stage II or stage III sporadic colorectal cancer is superior to CD44 expression for predicting progression. Int. J. Clin. Exp. Pathol. 2015, 8, 692-701. [PubMed]

80. Ma, L.; Dong, L.; Chang, P. CD44v6 engages in colorectal cancer progression. Cell Death Dis. 2019, 10, 30. [CrossRef] [PubMed]

81. Hu, S.; Cao, M.; He, Y.; Zhang, G.; Liu, Y.; Du, Y.; Yang, C.; Gao, F. CD44v6 targeted by miR-193b-5p in the coding region modulates the migration and invasion of breast cancer cells. J. Cancer 2020, 11, 260-271. [CrossRef]

82. Lipponen, P.; Aaltoma, S.; Kosma, V.M.; Ala-Opas, M.; Eskelinen, M. Expression of CD44 standard and variant-v6 proteins in transitional cell bladder tumours and their relation to prognosis during a long-term follow-up. J. Pathol. 1998, 186, 157-164. [CrossRef]

83. Zhang, X.H.; Cheng, D.B.; Ji, L.; An, H.W.; Wang, D.; Yang, Z.X.; Chen, H.; Qiao, Z.Y.; Wang, H. Photothermal-promoted morphology transformation in vivo monitored by photoacoustic imaging. Nano Lett. 2020, 20, 1286-1295. [CrossRef]

84. Cheng, D.B.; Qi, G.B.; Wang, J.Q.; Cong, Y.; Liu, F.H.; Yu, H.; Qiao, Z.Y.; Wang, H. In situ monitoring intracellular structural change of nanovehicles through photoacoustic signals based on phenylboronate-linked RGD-dextran/purpurin 18 conjugates. Biomacromolecules 2017, 18, 1249-1258. [CrossRef]

85. Xiao, B.; Hong, L.; Cai, X.; Mei, S.; Zhang, P.; Shao, L. The true colors of autophagy in doxorubicin-induced cardiotoxicity. Oncol. Lett. 2019, 18, 2165-2172. [CrossRef]

86. Chen, C.; Lu, L.; Yan, S.; Yi, H.; Yao, H.; Wu, D.; He, G.; Tao, X.; Deng, X. Autophagy and doxorubicin resistance in cancer. Anti-Cancer Drugs 2018, 29, 1-9. [CrossRef] [PubMed]

87. Mulcahy Levy, J.M.; Thorburn, A. Autophagy in cancer: Moving from understanding mechanism to improving therapy responses in patients. Cell Death Diff. 2020, 27, 843-857. [CrossRef] [PubMed] 
88. Lin, Y.X.; Wang, Y.; Qiao, S.L.; An, H.W.; Wang, J.; Ma, Y.; Wang, L.; Wang, H. “In vivo self-assembled” nanoprobes for optimizing autophagy-mediated chemotherapy. Biomaterials 2017, 141, 199-209. [CrossRef] [PubMed]

89. Liu, W.J.; Zhang, D.; Li, L.L.; Qiao, Z.Y.; Zhang, J.C.; Zhao, Y.X.; Qi, G.B.; Wan, D.; Pan, J.; Wang, H. In situ construction and characterization of chlorin-based supramolecular aggregates in tumor cells. ACS Appl. Mater. Interfaces 2016, 8, $22875-22883$. [CrossRef] [PubMed]

90. Muz, B.; de la Puente, P.; Azab, F.; Azab, A.K. The role of hypoxia in cancer progression, angiogenesis, metastasis, and resistance to therapy. Hypoxia 2015, 3, 83-92. [CrossRef] [PubMed]

91. Kim, S.B.; Lee, T.H.; Yoon, I.; Shim, Y.K.; Lee, W.K. Gold nanorod-photosensitizer complex obtained by layer-by-layer method for photodynamic/photothermal therapy in vitro. Chem. Asian J. 2015, 10, 563-567. [CrossRef] [PubMed]

92. Turner, J.H. An introduction to the clinical practice of theranostics in oncology. Br. J. Radiol. 2018, 91, 20180440. [CrossRef] [PubMed]

93. Sun, Y.; Zhang, Y.; Gao, Y.; Wang, P.; He, G.; Blum, N.T.; Lin, J.; Liu, Q.; Wang, X.; Huang, P. Six birds with one stone: Versatile nanoporphyrin for single-laser-triggered synergistic phototheranostics and robust immune activation. Adv. Mater. 2020, $32,2004481$. [CrossRef] [PubMed] 